\title{
Entrepreneurship and Knowledge Management: Knowledge Requirements, Utility, Creation, and Competency
}

\author{
Denzil PILLAY and Brian BARNARD*
}

Wits Business School, University of the Witwatersrand, South Africa

\begin{abstract}
The study examines knowledge management in the context of entrepreneurship: in particular, how entrepreneurs utilize and create knowledge, and build on knowledge as a core competency. Scientific research (SR) as knowledge type, and its relevance to the entrepreneur, are also investigated. With regards to knowledge creation, entrepreneurs excel at speed, originality and relevance, creativity, and business acumen. They have well-developed knowledge bases, and synthesize a lot of knowledge. Entrepreneurs both push and pull knowledge. The entrepreneur may source and acquire knowledge to advance and close the knowledge gaps of an identified opportunity, or may peruse knowledge in search of opportunity. The study elaborates on the relationship between knowledge and innovation, as well as the relationship between knowledge, creativity, and innovation. Entrepreneurs extensively consume scientific research, particularly to expand their knowledge bases. Similar to knowledge, entrepreneurs both push and pull scientific research. The extent by which they pull scientific research is determined by the extent that their opportunities require it. Entrepreneurs may also look to find application for scientific research as output. In this regard, the quality - measured as relevance - of the scientific research is important. Although presently and practically in shambles, collaboration between entrepreneurs and universities, can unlock further opportunities and value in this regard. Collaboration is much dependent on healthy relationship that permits bidirectional input and feedback.
\end{abstract}

Keywords: Entrepreneurship, innovation, knowledge, knowledge base, knowledge management, science, academic entrepreneurship

JEL Classification: O30, L26

\section{Introduction}

Alavi and Leidner (2001) state that knowledge is a core element of a firm's strategic management. It is seen to be entrenched and embedded in the organization, as it is found in its culture, routines, systems,

\footnotetext{
* Corresponding Author:

Brian Barnard, Wits Business School, University of the Witwatersrand, South Africa

Article History:

Received 2 February 2019 | Accepted 21 March 2019 | Available Online 29 March 2019

Cite Reference:

Pillay, D. and Barnard, B., 2019. Entrepreneurship and Knowledge Management: Knowledge Requirements, Utility, Creation, and Competency. Expert Journal of Business and Management, 7(1), pp.44-81.
}

This paper has previously been included in an open access repository - SSRN. 
policies and the individual employee. The value of knowledge is extracted by utilizing strategies like benchmarking, technology transfer and employee development etc. Individuals and organizations combine tacit and explicit knowledge to create new knowledge and expertise. This resource, if used appropriately, can be a differentiator, lead to rapid response, innovation, and deliver a superior competitive advantage to a firm.

Building on the fact that knowledge can constitute a core competency and strategic asset, a number of things point to the increasing importance of knowledge with regards to entrepreneurship : Knowledge elements can be recombined to form new inventions (Powers and McDougall, 2005). Science and technology increasingly overlap and jointly contribute to innovation (Ahuja and Katila, 2004). It is now progressively common for companies to partner with universities for R\&D collaboration. The increasing predominance of science and scientific research in entrepreneurship, is illustrated by academic entrepreneurship and its success. Academic research is increasingly transferred to the marketplace (Grimaldi et al., 2011), and universities that commercialize their research increasingly contribute to economic development (Laukkanen, 2003). High-tech industries are collaborating with university research more and more to fuel the creation of new companies, products and processes (Powers and McDougall, 2005). Goethner et al. (2012) note that academics who turn to entrepreneurship, create commercial products, start companies and sell research knowledge and inventions to the market. In order to generate highly advanced and innovative technologies, people with expert knowledge and talent as a key human capital resource are required. It is believed that start-ups associated with academic entrepreneurs would perform better than others.

Entrepreneurs create new knowledge as part of innovation and venturing. Also, entrepreneurs extensively build on their knowledge base. Still, little is known how entrepreneurs specifically employ, apply, and practice knowledge management, particularly as knowledge creation and knowledge reuse. When distinguishing between relatively "cheap" knowledge creation (creative problem solving exercises, like brainstorming; action research) and relatively "expensive" knowledge creation (basic research, applied research, R\&D), it is possible to allude to the quality or depth of knowledge creation. Also, it can be argued that knowledge creation and the depth of knowledge creation differentiate entrepreneurs, and also help to differentiate opportunity entrepreneurship from necessity entrepreneurship. Clearly, knowledge and knowledge creation can be a core competency for the entrepreneur, particularly "tech-entrepreneurs".

The study investigates how entrepreneurs perceive and use knowledge and knowledge creation as a core competency and differentiating factor. It examines how entrepreneurs identify and assess or grade knowledge gaps, particularly knowledge gaps that is believed to hold opportunity. It considers how entrepreneurs perceive and use academic research as knowledge type - their perceptions regarding its usefulness and utility.

The study addresses the following research question: how do entrepreneurs perceive and use knowledge and knowledge creation as a core competency?

- What do entrepreneurs perceive as the requirements for knowledge to be a core competency? What do entrepreneurs perceive as knowledge and knowledge creation requirements for entrepreneurship and innovation?

- How do entrepreneurs perceive academic research as knowledge type and knowledge source? How do entrepreneurs incorporate and use academic research as knowledge type and knowledge source?

The study reflects on how entrepreneurs perceive and use knowledge and knowledge creation as core competency and strategic resource. It contributes to the literature on knowledge, knowledge management, opportunity, opportunity recognition and entrepreneurship.

No attempt is really made to segment and constrain according to industry type. The impact of industry is not taken to be relevant. The study focuses on experienced entrepreneurs. It is believed that experienced entrepreneurs have developed mature perceptions regarding knowledge in the context of opportunity and entrepreneurship.

\section{Literature Review}

\subsection{Knowledge Management}

Alavi and Leidner (2001) declare knowledge as a key resource in business. The purpose of a Knowledge Management system (KMS) in an organisation is to support the creation, transfer, and the application of knowledge. It is distinguished that knowledge is the core element of a firm's strategic management. Knowledge is seen to be entrenched and embedded in the organization, as it is found in its culture, routines, systems, policies and the individual employee. This resource, if used appropriately, can be a competitive differentiator and deliver an advantage to a firm. Knowledge resources are socially complex, hard to replicate and can lead to a sustainable competitive advantage in the business. This is achieved through exploiting the value of knowledge within the organisation, by focusing on employing strategies like 
benchmarking, knowledge audits, best practice transfer and employee development. Knowledge can lead to rapid response and innovation. Therefore the incorporation and objective of a knowledge management system, should perform the following: 1) make knowledge available and display its application to every individual within the organizations; 2) Create a knowledge culture; share and transfer knowledge between each other; 3 ) Build knowledge infrastructure, technical and other; facilitate and encourage collaboration. The Knowledge management $(\mathrm{KM})$ framework generally entails the following: creation, storage/ retrieval, transfer, and application.

\subsubsection{The Nature of Knowledge}

Alavi and Leidner (2001) note that a number of authors simply define a common, simplistic definition of knowledge, by separately distinguishing between knowledge, data and information. A general view of knowledge is that there are various slight permutations of data that is raw numbers and facts, information is processed data, and knowledge is vetted information. Information is also classified as raw data that has not yet been processed. It is further established that knowledge determines what is information (informative), and how data is sourced. Knowledge is considered to be well defined, articulated, verbalized and structured information, which needs to be cognitively processed to form meaning.

Alavi and Leidner (2001) define various perspectives of knowledge as: a state of mind, an object, a process, a condition of having access to information, or a capability. Knowledge is described as a state of knowing, and is achieved through experience or learning. The viewpoint on knowledge as a mind-set, places emphasis on individuals developing their personal knowledge, to help solve organizational problems. Further to this, knowledge can be stored and manipulated (i.e., object). Another view of knowledge is that it is a process of knowing and acting at the same time. The aspect of having knowledge at your disposal, allows you to be prepared and learn from past experience. This capability prepares the individual to interpret information, and influences learning and decision making.

Blackler (1995) argues that the traditional views of knowledge were depicted as: intangible plans, concept of social structure, importance of situated skills, pragmatic knowledge, sociologists of science, deeprooted assumptions about the advantaged status of obvious abstract knowledge and studying knowledge creation as a cultural process, and by de-emphasizing predictable differences between people and technology. The meaning of knowing is further defined as mediated, situated, provisional, pragmatic and contested.

Lam (2000) delineates tacit knowledge as a knowledge type. It has an impact or place in knowledge, and requires cognitive processing. This includes the tacit nature of human knowledge, and the combination of self and shared learnings or experiences. This tacit human knowledge is a large part of things such as skills, know how, routines, and techniques which are difficult to simplify, and hard to explain or communicate in some kind of code.

\subsubsection{Types of Knowledge}

Alavi and Leidner (2001) point out the difference between tacit and explicit knowledge. Tacit knowledge is defined as performed in action (actual doing), experience, and being a part of it (involvement). The explicit sphere of knowledge is defined as how knowledge can be communicated so that it is easily defined, articulated, codified, and symbolically communicated or expressed through a common language to others. Lam (2000) lists three distinct differences between explicit and tacit knowledge. Explicit knowledge can be expressed through code, such as a language, compiled through systematic thinking, gained through formal study, and kept in different forms. Tacit knowledge, on the other hand, is instinctive and difficult to express and articulate, gained by practical experience and actually doing the work, and subjective.

Alavi and Leidner (2001) note that knowledge can be classified as individual versus collective knowledge. Individual knowledge is created by and stored within the individual. Whereas social knowledge on the contrary, is created by the collective actions of a group. This explains the need to collect and store large files of explicit knowledge, which has a higher value, and requires IT for example, to capture and manage the knowledge. Simply, the explicit-tacit and individual-collective dimensions of knowledge lead to four classes of knowledge, such as: embrained, embodied, encoded and embedded.

Alavi and Leidner (2001) argue that there are other types of knowledge classes, such as: declarative (know-about or knowledge by acquaintance), procedural (know-how), causal (know-why) and conditional (know-when, and relational know-with). Knowledge is also classified by customer information, products, processes, competitors, best practices, know-how and heuristic rules, patterns, software code, business processes, and models; architectures, technology, and business frameworks; and project experiences proposals and work plans, etc.

Blackler (1995) notes there are a minimum of five types of knowledge that can be identified in 
research: 1) embrained, 2) embodied, 3) encultured, 4) embedded, and 5) encoded. Embrained knowledge is mentally dependent on the brain to process, by its conceptual talents and cognitive aptitudes (knowledge that or knowledge about). Embodied knowledge refers to performing or doing, and relates to a part of explicit knowledge (knowledge how, and knowledge of acquaintance). Encultured knowledge builds on a common understanding. Embedded knowledge is located in an organized process, formal procedures, systems, etc. Encoded knowledge refers to information that gives meaning to symbols and signs.

Blackler (1995) developed categories of knowledge found in organizations, and simply differentiated: 1) expert-dependent organizations, which depend heavily on embodied knowledge; 2) knowledge-routinized organizations, which depend heavily on embedded knowledge; 3) symbolic-analyst dependent organizations, which depend heavily on embrained knowledge; and 4) communication-intensive organizations, which depend heavily on encultured knowledge.

Markus (2001, p. 62) defines other knowledge types: "general knowledge (including, for example, explicit scientific knowledge) and specific knowledge (including knowledge of the local context), technical or contextual knowledge, declarative knowledge (knowledge about facts) and procedural knowledge (knowledge about how things are done), rationale knowledge (knowledge about why things were done, as in the design of software products) and analytic knowledge (the conclusions reached by applying declarative and procedural knowledge to a particular fact domain)."

De Jong and Ferguson-Hessler (1996, p. 105) note the qualities of knowledge as: "level (deep or surface) of knowledge, generality of knowledge, level of automization of knowledge, modality of knowledge, and structure of knowledge". "Knowledge is attributed a wide variety of properties and qualities, for example: generic (general) knowledge, domain specific knowledge, concrete and abstract knowledge, formal and informal knowledge, declarative and proceduralized knowledge, conceptual and procedural knowledge, elaborated and compiled knowledge, unstructured and structured knowledge, tacit or inert knowledge, strategic knowledge, knowledge acquisition knowledge, situated knowledge, and meta-knowledge."

Esteves et al. (2003) note project knowledge types as: business knowledge, technical knowledge, product knowledge, company-specific knowledge, and project management knowledge.

Faulkner (1994) categorises knowledge types related to innovation as: 1) the natural world, 2) design practice, 3) experimental $\mathrm{R}$ and $\mathrm{D}, 4$ ) the final product, and 5) knowledge connected to knowledge.

\subsubsection{Knowledge Creation}

Both Lam (2000), and Alavi and Leidner (2001) note that new knowledge creation requires blending explicit and tacit knowledge. Organizational knowledge requires the combination of tacit and explicit knowledge to expand, build, change and create new knowledge. They note that four different types of knowledge creation have been identified: socialization, combination, externalisation, and internalization. The conversion processes of the above knowledge types, demonstrate knowledge flows from tacit to new tacit (socialization), explicit to new explicit knowledge (combination), tacit to new explicit (externalisation) and new explicit to tacit (internalization).

Alavi and Leidner (2001) note the environment of knowledge, and the conditions that enable new knowledge creation. An organization's knowledge creating space (KCS) is pertinent to new knowledge creation. There are four types of KCS that matches to the four modes of knowledge creation: 1) Originating KCS is whereby individuals meet at a common location and specific time, communicate through face to face interactions, and share knowledge or experience; 2) Interacting KCS allows individuals to share knowledge through a mechanism of conversation and collaboration; 3) Cyber KCS refers to a virtual space of interaction, such as online platforms, whereby individuals collaborate to share explicit knowledge; 4) exercising KCS requires participation and on job training, so that continuous individual learning is achieved.

Alavi and Leidner (2001) state that individual memory is built up over time, and accounts for experiences, observations and one's actions. Collective or organizational memory is defined as how an organization uses knowledge from historical events and experiences, and develop on it to benefit the organization's activities going forward. The memory of the organization is not stored in an individual, but rather in mechanisms such as the culture of the business, transformations (production processes and work procedures), structure (formal organizational roles), ecology (physical work setting) and information archives (both internal and external to the organization) (Walsh and Ungson, 1991).

Lam (2000) argues that the knowledge structures in organizations are primarily based on societal influence. The leading roles of this nature of knowledge, is the human and cultural aspect, which is found in the fabric of organizations, educational areas, workforce types in the market, and professions.

Markus (2001) notes that knowledge includes both knowledge creation and knowledge reuse, and stresses the place of knowledge reuse. New knowledge created as part of the design, research, or development 
of a new product, is seen as having a higher priority, difficult, and time consuming. The reuse of knowledge is brought about by sharing experiences, and troubleshooting technical challenges. This reuse of knowledge is viewed as simpler, as the process is as follows: 1) capture or record; 2) format as required; 3) route or grant access to its users; 4) reuse knowledge.

Alavi and Leidner (2001) note that a vital procedure of knowledge management, is the transfer of knowledge, so that it can be stored in an environment where it can be easily accessed and worked with. The problem arises with the location and storage of knowledge processes, as they are normally flawed (Huber, 1991). Gupta and Govindarajan (2000) devised a framework for knowledge transfer, which comprises of a process of five facets:

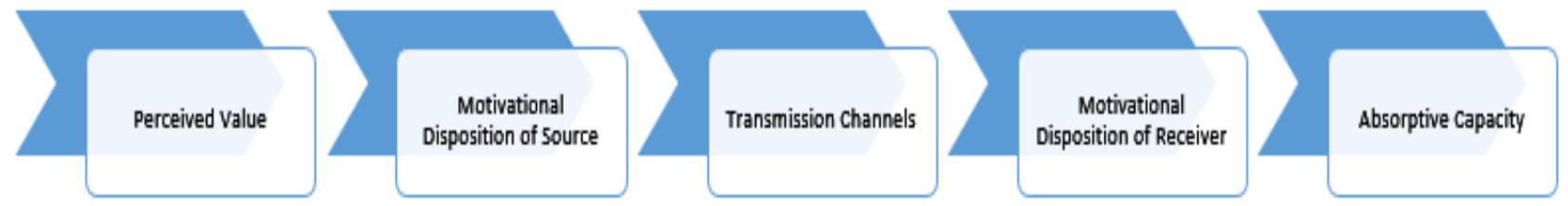

Figure 1. A framework for knowledge transfer (Gupta and Govindarajan, 2000)

Step 1 - Perceived value: refers to the perceived worth of the knowledge, also given its source.

Step 2 - Motivational disposition of the source: is the eagerness or willingness to share knowledge.

Step 3 - Transmission channels: are mediums used to facilitate this knowledge transfer, to achieve optimum results, both informal and formal (i.e. meetings, conversation, emails, seminars, etc.).

Step 4 - Motivational disposition of the receiver: is the eagerness or willingness to share and acquire knowledge from the source.

Step 5 - Absorptive Capacity: is ability to receive the knowledge and store it. This is the most difficult, as it depends of the receiver's mental processing of the knowledge.

Alavi and Leidner (2001) argue that having original knowledge is vital, but knowing where that knowledge is stored, i.e. most meta-data, is just as important. Three core elements facilitate the merger of knowledge: 1) directives, 2) organizational routines, and 3) self-contained task teams. Directives are knowledge that is derived from specialists, who simplify knowledge, so that non-specialists can easily understand the knowledge, and apply it quickly. It includes: rules, processes, regulation, procedures and instructions, etc. The next mechanism of integrated knowledge is organizational routines, such as: evacuation drills, aircraft in maintenance checks, etc. The third mechanism - self-contained task teams - are required when an organization needs specialists, to come together to brain storm, troubleshoot, and derive best solutions for complex and unpredictable tasks.

Castellanos et al. (2004) note that students derive some of their many intangible skills from educational institutions, one of them being knowledge based on intellectual capital. The research-development-transfer capital (R\&D\&T capital) is dependent on the creation of scientific and technical knowledge, and the exchange of knowledge between social environments, i.e. businesses, intuitions, and other public agents. They list a few lead indicators of intellectual capital: 1) Scientific and technical knowledge, more so the knowledge that can be used and built on by university researchers; 2) Specific skills and knowledge with regards to its method, focus on application, and transfer; 3) Knowledge and acceptance of the need for applied and basic research, i.e. a need for knowledge pertaining to the generation of knowledge through interaction between firms, companies and institutions; 4) The knowledge required to solve problems for an organization, a society, and institutions, which requires different expert groups to come together.

\subsection{Scientific Knowledge}

Heilprin (1995) defines science as a description of existence. Scientific procedures provide an understanding of perception or logic, processes of mental categories, classifications, groupings and traits, or single characteristics. According to Ahuja and Katila (2004), the definition and purpose of science, is the validation of facts, and is built around numerical rules or laws, so that it links facts to each other. The ultimate purpose of science is to develop new knowledge, and find solutions to core problems, which also aids in developing scientific laws and theories that describe, explain, and delineate the intricacies of nature (Lee et al., 2016). According to Hong (1999), technological knowledge its more than hardware or artifacts. Keller (2008) sees technology as a system of knowledge, that has application. Technology is knowledge with real-life application.

Suenaga (2016) notes the objective of science is to provide clarity of natural phenomenon and 
technology. Ahuja and Katila (2004) argue that technology is used to develop knowledge into artifacts, so that we can extract benefit from it, unlike science, which uses knowledge to build on, enrich and to understand. Adams (1997) points out that scientific findings are largely aimed at nature and its surroundings, yet technology mainly aims at the physical world, and its organizational requirements. Academic research produces improved meaning to models, analysis to theories, and helps to understand trends and predict future patterns. This provides a platform to gain analytical traction, as it reduces variables and help simplify studies. Business research and development, on the other end, uses it to create and produce purposeful artifacts. These creations are unique, complex and require many processes to ensure it is not easily imitated, which can be described as analytically intractable (Pavitt, 1998).

The distinctions between science and technology are predominately focused in their individual fields (Suenaga, 2016). Pavitt (1998) notes that basic research builds on primarily basic research in science, and scientific research cite other scientific papers more than patents. Technology research works the other way around: technology research predominately builds on patents, and patents are cited more.

Rosenberg and Nelson (1994) note that the requirements for scientific knowledge, and the knowledge for new parts for commercial use, are totally opposite. When the market requires new parts, there is seldom a need to employ scientific knowledge. The technological market demand can be better met by technological knowledge than scientific knowledge (Lee et al., 2016). Suenaga (2016) argues that the requirements for analysis of scientific knowledge are less stringent, due to the fact that is codified. Conversely, technological knowledge is implicit, and requires doing, skill, and experience to employ. Furthermore, the economic worth of technology differs from that of science, as they are valued differently (Suenaga, 2016).

Cao (2015) points out the differences of science and technology against their ontological, epistemological, and methodological premises. From the ontological perspective, science is described as artifacts in nature, and relates to findings in theory, while technology implies designing and creating technology inventions as human made artifacts. With regards to epistemology, both science and technology are created by man and classified into different realms. Scientific knowledge is theoretical and declarative (to know what and know why). Technological knowledge is of a practical nature, which can be described as procedure driven, independent, procedural, autonomous, and descriptive (to do what and the know how). The methodology of science starts with hypotheses, and the results of the research will verify the stance taken, by proving or disproving the hypotheses. Technology methodology primarily focuses on practical experience, which mixes aspects of design, building, creating, and innovation; with products being tried and tested until they work correctly.

The economic attribute of science and technology is considered to be more like a private good, than a public good (Ahuja and Katila, 2004; Brooks, 1994; Pavitt, 1998; Rip, 1992; Rosenberg and Nelson, 1994).

\subsubsection{The Contribution of Science to Innovation}

Ahuja and Katila (2004) note that an overlap of science and technology leads to the development of innovation. Knowledge elements can be recombined to form new inventions. At some point this runs dry, and focus again turns to science, to revive the process. Technology introduces innovation, and science adds an extra dimension to innovation, which allows for various combinations and re-combinations. The introduction of science to innovation further introduces a deeper understanding of cause and effect relationships, which helps the inventor create extreme innovation.

Pannell (1999) delineates the inter-relationship between basic and applied research as follows: 1) basic research generates basic knowledge; 2) applied research generates applied knowledge; 3) basic knowledge affects the production of applied knowledge via applied research; 4) applied knowledge affects the production of basic knowledge via basic research; 5) basic research generates applied knowledge; 6) applied research generates basic knowledge; 7) foreign knowledge contributes to local knowledge; 8) knowledge dissipates or becomes obsolete; 9) knowledge contributes to social welfare. Brooks (1994) notes the contributions of science to technology: 1) science as a direct source of new technological ideas; 2) science as a source of engineering design tools and techniques; 3) instrumentation, laboratory techniques, and analytical methods; 4) the development of human skills; 5) technology assessment; and 6) science as a source of development strategy. On the other hand, the contributions of technology to science are: 1) technology as a source of new scientific challenges; and 2) instrumentation and measurement techniques.

Lee et al. (2016) note that the clear distinctions between industries, markets and knowledge, such as science and technology, are slowly becoming distorted. It is essential to understand the combined role of science and technology, and the influential outcome it has on innovation. It is commonly known as the convergence of science and technology. Science has a huge impact on innovation, as it aids in the development of inventions, by providing solutions to identified problems, and speeds up the innovation process. 
Lee et al. (2016) argue that, by converging science and technology as two distinct knowledge sources, new ways of thinking can be derived and explored. This convergence will be particularly valuable during the establishment of an invention. The convergence of knowledge from different sources inspires the inventor. Science aids technology to arrive at solutions, by using fundamental theories to establish effective methods. Engineers and scientists working together and complementing each other, create synergies.

Beukel et al. (2014) depict the deployment of knowledge sources to solve problems. The learning that takes place in organizations, builds on explorative and exploitative search methods. Search and problem solving may use methods of different cognitive direction. Forward looking search is explorative, and focuses on the choice and impact of actions. Backward looking search is exploitative, and employs existing knowledge.

\subsubsection{Scientific Method}

Scientific knowledge is the generation of models and theories that are testable, revisable, explanatory, conjectural, generative, and used to explain the world, events, processes, or properties (Windschitl et al., 2008). Most of science can only be indirectly validated, thus the need for models and theories (Lee, 1989).

The application of the scientific method (SM) may encounter numerous practical issues, such as: 1) Inability to control observations due to data scarcity; 2) Making controlled deductions; 3) Allowing for replicability, and 4) Allowing for generalizability (Lee, 1989). SM does not truly recognize the contribution of inductive reasoning to theory development (Haig, 1995). SM as paradigm does not necessarily guarantee good results: though it may come across as a cut-and-dry process, the quality of its application, determines the quality of the results (Windschitl et al., 2008).

Modelling, grounded theory and statistical analysis form viable alternatives or complements of SM. Modelling constitutes the evaluation of an idea against real life observations (Windschitl et al., 2008). Grounded theory comprises bottom up, rather than top down, theory construction from data and evidence (Haig, 1995). Statistical analysis builds on correlation, rather than causation, and data are analysed for trends and patterns (Anderson, 2008).

Furlong and Oancea (2005) note that the OECD Frascati Manual (Guidelines for Collecting and Reporting Data on Research and Experimental Development) defines applied research as: "original investigation undertaken in order to acquire new knowledge, directed towards a specific practical aim or objective". The other objectives of applied research put forward, are to establish potential usages of basic research, or to find new procedures, or to drive an objective to yield a specific and pre-set outcome. Although not accurate, a common distinction is made between research that is academically driven, and research that is practitioner driven, or practice-based research. Other common distinctions include "pure", "applied" and "strategic" research. They accordingly distinguish between academic-led theoretical pursuits (e.g. historical research), applied and practice based research, and research informed practise. It may be extremely difficult to assess the real worth and impact of a piece of research. Rather, emphasis should be placed on the potential worth it will create. A research project can be assessed in terms of its (potential) influence, contribution and growth or developmental potential.

\subsection{Academic Entrepreneurship}

Grimaldi et al. (2011) argue that it is a difficult task to divide the skills required to be a successful scientist, and the skills required to be a successful entrepreneur. Powers and McDougall (2005) note that the success of high-technology industries demonstrates that the creation of new companies, products, and processes builds on university research collaboration. They state that universities have received considerable investment from industries, which has increased from US\$630 million in 1985, to US\$1.896 billion in 1998. It is very small in relation to state funding, but it is seen that industry-sponsored R\&D is growing rapidly, to support for R\&D at universities. Grimaldi et al. (2011) note that trends display a great increase in technology driven economic development initiatives, which is primarily aimed at boosting technological entrepreneurship in universities, through patenting, licensing, start-up creation, and university-industry partnerships. "Academic entrepreneurship" is the term used, as the aim of academic scientists is to capitalize on their innovations, by taking it to market. There has been an escalation in the global recognition of public and private university research as a medium of knowledge commercialization. Increasingly, policy makers are looking to universities for economic benefits from enhanced entrepreneurship through knowledge and research commercialization.

Grimaldi et al. (2011) point out that due to the ever escalating academic patents, and licensing of the results, the majority of universities now have technology transfer offices. Transferring academic research to the marketplace can be done through a number of instruments, such as university patents, generation of academic spin-offs, collaborative research, contract research, and consulting and networking with practitioners. Furthermore, it includes lecturing, co-publishing with industry, and sharing personal learning 
experiences, e.g. exchange programmes and joint supervision. Informal technology transfer occurs occasionally, and usually is concluded by an agreement, which renders the technology transfer office (TTO) irrelevant in most cases.

Haeussler and Colyvas (2011) note that the objective of technology transfer (TT) is to further enable innovation, to escalate knowledge flows to companies, and to increase IP and academic involvement in commerce.

Haeussler and Colyvas (2011) state that TT represents how scientific findings pass from one entity to another, for greater growth and enhancement for capitalization. Basically, the game has changed, with greater focus on the value of research (ensuring research is of value), and with increased collaboration, to speed things up and make it more effective. The traditional ways of moving academic research into industry science has changed. Government policy - incentives and initiatives - play a bigger role, and the system is far more interwoven.

Bozeman et al. (2013) note that, even though industry research differs significantly from academic research, the majority of industrial research borrows from academic research created at universities.

Laukkanen (2003) point out that previously it was the norm to make preconceived assumptions, like: 1) universities are led by "pure" academic standards, and 2) only have two purposes: high level research, and transmission of knowledge. This, in addition, should transpire amicably, and be free of interest from industry or business. There are some countries which do not allow any connection with or control of the research process of universities. Today, it is quite different, as innovation and economic growth are influenced by universities, and universities can help to turn around regions in trouble. A new segment of labour, classified as academe, is growing rapidly. It is viewed as a major source of new technologies and business ventures, and is also regarded in some cases as a regional development engine.

Klofsten and Jones-Evans (2000) state that the knowledge derived from academic intuitions are not seen as stand-alone knowledge. The European government at all levels view higher education as a major player in the economy. It is seen to drive income and employment, to contribute to cultural life, and to promote economic development. Many countries bear testament to this: universities are seen to be increasingly playing a major role in cities, and attracting public and businesses to services grounded in university activities. Therefore, in brief, they boost jobs, and the improvement of jobs, in the local sector, and constitute a major source of future employment opportunities, particularly in the high technology and knowledge based sectors.

Powers and McDougall (2005) point to immense uptake in the use of university research for commercial benefit. In 2000, 347 new commercial products entered the market, which were attributed to licensed technologies from 88 universities. The amount of new licenses and options improved from 3914 in 1999 , to 4362 in the year 2000. Start-up companies contributed to 454 out of 626 licenses, and it shows a major drive of entrepreneurial activity to commercialize academic research.

\subsubsection{The Relationship between Academics and Entrepreneurship}

Goethner et al. (2012) argue that academic research contributes significantly to new products, processes, and even whole (new) industries. Scientists who turn to entrepreneurship, create commercial products, start companies and sell research knowledge and inventions to the market.

Powers and McDougall (2005) note that, in order to generate highly advanced and innovative technologies, it requires people with expert knowledge and talent, as a key human capital resource. A wealth of this primary resource can be found amongst university faculties. It has been acknowledged that an important relationship exists between the repute of university scientists and company performance.

Klofsten and Jones-Evans (2000) identify 8 categories of academic entrepreneurship, which are: 1) Large scale science projects; 2) Contracted research; 3) Consulting; 4) Patenting or licensing; 5) Spin off firms; 6) External teaching; 7) Sales; 8) Testing. The categories are differentiated by their extent of external interaction with industry. Consulting and contract research are found to be the most preferred of all the categories of technology transfer.

Powers and McDougall (2005) note that there are numerous reasons as to why industries are inclined to spend money on R\&D at universities. For example, drug companies may not possess the equipment to perform research for trials; or, a company has created a prototype, but requires it to be validated through a legal route. In addition, a co-operative partnership with academic scientists helps companies delineate and implement their strategic paths. Lastly, in new industries, like biotechnology, companies depend heavily on elementary scientific research from universities. Research shows that good university-industry relationships and links, realize a number of benefits, for example, faculty consulting to industry, faculty involvement in new firms, and faculty and university equity participation in start-up firms. This participation in industry-sponsored R\&D projects, establishes an entrepreneurial ethos in an university. 
Haeussler and Colyvas (2011) point out that in many countries, there is a link between publication productivity and academic entrepreneurship. The higher the number of publications by scientists, the greater the possibility of commercialization of findings. At the same time, it draws the attention of leading scientists. The difference between nano-science patentors and non-patentors shows that scientists who get their work patented and published, are more efficient, judging by publication rates. It further postulates a close relationship between publication and commercial activity: organizations and researchers working together, instead of apart.

Toole and Czarnitzki (2007) state that academic work proposes that specialist scientists, such as discovery and especially star scientists, possess specialized knowledge, network contacts, or reputations of value. Therefore, the belief is that start-ups associated with academic entrepreneurs should perform better than others. Bozeman et al. (2013) argue that in all areas of scientific and technical research, collaborative research has now become the standard, according to extensive results. Collaboration is described as when humans come together and contribute their human capital for the purpose of knowledge generation. It is now progressively common for companies to partner with universities for $\mathrm{R} \& \mathrm{D}$ collaboration. The objectives of companies when collaborating with universities, are to create research synergies, stay abreast of advances in technological developments, and to optimise $R \& D$ costs. Collaboration with universities helps companies to grow their knowledge base, and to enhance their production processes.

\subsubsection{Technology Transfer}

Haeussler and Colyvas (2011) note that different forms of technology transfer (TT), such as consulting, patenting and founding, require qualitatively unique forms of partnerships with industry, and unique levels of commitments. In addition to consulting on a contractual basis, scientists may be approached to consult on a long term basis, or to take on an advisory board membership role, for example. A majority of scientists are involved on a project basis. Scientists are attracted to consulting, as it gives them insight into practice, stimulates fundamental research, and surfaces student career opportunities.

Powers and McDougall (2005) state that the conventional process of universities to create and commercialize technology, was through licensing of the intellectual property (IP) to an established company, who would improve and develop it into a marketable item. The fee structure for IP would normally be an upfront payment, with follow-up payments or royalties from the sale of each unit. Universities are now increasingly taking on riskier avenues of technology transfer, such as partnering with start-ups or licensing inexperienced companies. The different options taken by universities, show their pursuit of commercialization, to gain improved revenue streams, greater optimization and direction of university-firm benefit, and greater public respect and validity. In certain cases, they attempt to replicate the success of technology firms, like Xerox and Polaroid, to attain economic growth, by taking advantage of university born inventions.

\subsection{Conclusion}

Knowledge evidently is a strategic resource that can lead to competitive advantage. The creation, storage, transfer and application of knowledge are crucial aspects to consider. Knowledge and science increasingly play prominent roles in innovation and entrepreneurship.

Still, little is known as to how entrepreneurs perceive, approach, and utilize knowledge, and build and convert knowledge into opportunity. This study sets out to further examine the relationship between knowledge and opportunity, and consequently addresses the following research question: How do entrepreneurs perceive and use knowledge and knowledge creation as a core competency?

- What do entrepreneurs perceive as the requirements for knowledge to be a core competency? What do entrepreneurs perceive as knowledge and knowledge creation requirements for entrepreneurship and innovation?

- How do entrepreneurs perceive academic research as knowledge type and knowledge source? How do entrepreneurs incorporate and use academic research as knowledge type and knowledge source?

\section{Methodology}

In order to study the relationship between knowledge and opportunity, knowledge as core competency, and academic research as knowledge source, semi-structured interviews were carried out with experienced entrepreneurs, and purposive sampling was used. 10 experienced entrepreneurs were interviewed, all with at least 1 successful business, and at least 3 years entrepreneurship and innovation experience. Sampling was not constrained according to industry, as the impact of industry on the study was deemed negligible. Participants were identified through professional and business networks. Interviews on average lasted 1 hour. Interviews 
were recorded, transcribed, coded, and further analyzed.

\section{Results}

\subsection{What do entrepreneurs perceive as the requirements for knowledge to be a core} competency? What do entrepreneurs perceive as knowledge and knowledge creation requirements for entrepreneurship and innovation?

\subsubsection{Nature of Knowledge}

The dimensions of the entrepreneur's knowledge entail: 1) knowledge structures, 2) reliability and accuracy, 3) uniqueness, 4) utility, 5) speed, and 6) depth.

The entrepreneur is interested in the accuracy, reliability, worth, potential and application of knowledge. Models and frameworks are constructed to interpret and make sense of the world. Knowledge structures formed are generally very pragmatic, to ensure it can be easily applied, utilized and built upon. The entrepreneur considers the accuracy and reliability, and the newness or uniqueness - the entropy - of knowledge sources. Knowledge informs, creates awareness, and changes preferences and routines, patterns and culture. Knowledge unlocks new benefits. Knowledge is used to make a product more sophisticated. Competitors will naturally have less sophisticated products. Presently, knowledge is created much faster.

Different levels of knowledge exist. New knowledge creation (NKC) may require very focused, and very deep or sophisticated knowledge. NKC builds on existing knowledge already accumulated. NKC may entail and extend into areas of knowledge not yet fully explored or exploited. It may also pertain to progress where the entrepreneur is, and where he wishes to be or go. Depth of knowledge may also be industry-specific - some industries may (already) have a lot of accumulated embedded knowledge, and may have high standards, etc. that relate to knowledge.

\subsubsection{Evolution of Knowledge in the Context of Entrepreneurship}

The basic process of entrepreneurship, also in terms of knowledge in the context of entrepreneurship, has not changed much. What may have changed, is that knowledge transitions faster and is more readily available. The types of knowledge sources are generally the same, and have not really changed. Information flow has changed. The world is more connected. Projects and work are completed faster. Technology and technology use are more sophisticated. Life, lifestyles, interaction, and production have all changed. Therefore, knowledge itself, and what constitute as knowledge, have changed. Product knowledge frequently changes along the dimensions of knowledge regarding: 1) quality, 2) cost, and 3) extension (new features).

The general knowledge base, due to science, etc., has expanded. This affords greater understanding, and a lot more opportunities and ideas. Correspondingly, the accuracy of the entrepreneur has also improved - the entrepreneur's ability to predict what will (not) work has improved. Information and knowledge are now readily available, and far more widely accessible, but also less verifiable. Knowledge is becoming a commodity, that is acquired (in base form), and integrated and synthesized into higher levels.

\subsubsection{Future Context of Knowledge}

Knowledge creation and knowledge sources are also shaped by the future, the imminent future, and the prevailing vision of the future. The whole environment, lifestyle(s), (conducting) business, and (thus) entrepreneurship are changing, and with it, knowledge, knowledge sources, and how knowledge is sourced and accessed. The nature of opportunities, and how it is realized, are changing.

Online sources are very prominent. World class knowledge and information are available online from universities, from global sources. AI (artificial intelligence) is assisting and speeding up innovation. Machines and robots are increasing in prominence, and will further change the landscape. Automation and optimization will continue, particularly of the routine - what can be described as routine. People are and will generally be pushed to higher levels of innovation and creativity. It implies significant realignment, restructuring, and paradigm shifts.

\subsubsection{Radical Knowledge}

Radical knowledge (RK) as novel and disruptive knowledge, allows the entrepreneur to radically improve how he is serving his existing market. It may be associated with and related to radical innovation. It is generally associated with new technology, very specific and focused in application, and highly sophisticated. It is generally exclusive, and not easy to acquire, learn, or construct. It is in-depth, unique, and practically verified. It may imply explicit understanding. Really novel knowledge may take time to develop. It is cultivated, shaped, moulded, formed, and built up. It generally delivers competitive advantage. It is also composite knowledge that is integrated and synthesized to higher levels - pieced together. It is commonly 
generated, rather than sourced.

RK can be cultivated by 1) integrating diverse knowledge; 2) keeping up to date; 3) taking a basic idea, and expanding, inflating, and developing it; 4) mere creativity; 5) original and divergent thought; 6) extensive thought. It comes from comprehending, interpreting, and then integrating knowledge. It may be brought about, and become feasible, through sudden and unexpected developments and changes. Speed, capacity, accuracy, and dynamism may be very relevant to RK: The ability to 1) quickly search through vast amounts of knowledge; 2) quickly solve problems and provide a solution; 3) inflate, develop and add value to basic or principal ideas. Radical - new, original and divergent - thinking can lead to RK, but requires stepping out of conventional thinking and boundaries, pushing boundaries, and challenging the status quo. RK may require a lot of thinking and thought. It also requires a lot of experimentation, trial and error, and learning, and following through with implementation. Radical knowledge may also be obtained through lived experiences, specialist training, research or collaboration. Culture and environment equally play a role.

\subsubsection{High Value Knowledge}

High value knowledge (HVK) enables creative solutions to customer needs. Greater knowledge can translate into new, innovative, and higher value products. Knowledge reduces uncertainty and risk. By enabling and unlocking higher quality opportunities, it permits differentiation.

HVK may be difficult in very competitive markets, where competition is not local, but global. Some are of the opinion that it is getting more difficult to be original. For these reasons, incremental innovation is then seen to be a lot less riskier.

Table 1. Attributes of high value knowledge.

\begin{tabular}{|l|l|}
\hline Implementable. & Validated; proven. \\
\hline Practical; Applicable (high application); contextualized; customized. & Valuable. \\
\hline Original; revolutionary; resembles divergent or new thinking, or a paradigm shift. & Exclusive; differentiated. \\
\hline Sophisticated; specialist; custom; advanced; specific; niche; high IP. & $\begin{array}{l}\text { Composite; integrated; } \\
\text { synthesized. }\end{array}$ \\
\hline Accumulated; compounded. & Effort and resource intensive. \\
\hline Customer based. & Diverse knowledge base. \\
\hline $\begin{array}{l}\text { Solves fundamental problems, questions, issues, etc; closes deep and extensive } \\
\text { knowledge gaps. }\end{array}$ & \\
\hline
\end{tabular}

Table 2. Sources of high value knowledge.

\begin{tabular}{|l|l|}
\hline Literature; academic literature. & Experience, skill. \\
\hline $\begin{array}{l}\text { A certain highly relevant or radical knowledge } \\
\text { premise or foundation, that opens the door for } \\
\text { further exploration and knowledge development. }\end{array}$ & $\begin{array}{l}\text { Elaborate and comprehensive knowledge and understanding, } \\
\text { enabling the entrepreneur to discern trends, forecast } \\
\text { developments and direction, and recognize opportunities others } \\
\text { can't. }\end{array}$ \\
\hline Diverse knowledge. & Networking and collaboration; experts. \\
\hline Real-life problems. & Creative thinking. \\
\hline Unique, difficult to access knowledge sources. & \\
\hline
\end{tabular}

\subsubsection{Knowledge Gaps}

A knowledge gap (KG) can be identified as realizing a problem, and not possessing the knowledge to solve it. KGs are the knowledge necessary to make an idea or opportunity succeed - to implement it. A KG can also be defined as the discrepancy between an idea and its commercial success. Opportunities predominantly define KGs. Most knowledge gaps have very clear business implication. The opportunity embedded in the knowledge gap is very clear. In general, knowledge gaps are closely associated with opportunities. The value of a knowledge gap is then the value of the underlying opportunity. When identifying and recognizing opportunities, the underlying knowledge gaps are also identified and recognized. The entrepreneur assesses the (knowledge) gap between where he is and where he wants to go or be. 
Table 3. Identifying knowledge gaps.

\begin{tabular}{|l|l|}
\hline $\begin{array}{l}\text { The performance and success } \\
\text { of existing products. }\end{array}$ & Observing and studying perceptions, implementations, etc. \\
\hline Benchmarking. & Waste; inefficiencies. \\
\hline Market research. & $\begin{array}{l}\text { Developing comprehensive understanding; modelling; monitoring in greater depth, or in } \\
\text { greater time. }\end{array}$ \\
\hline $\begin{array}{l}\text { Market and customer } \\
\text { interaction. }\end{array}$ & Discrepancies between reality, and theory or models. \\
\hline $\begin{array}{l}\text { Business, industry, and } \\
\text { related experience. }\end{array}$ & $\begin{array}{l}\text { Inquiry - questioning, interrogating and challenging the premises and assumptions of } \\
\text { current knowledge bases, or that of a product, market or industry, and noting whether } \\
\text { there are loose ends. }\end{array}$ \\
\hline
\end{tabular}

\subsubsection{Knowledge Creation}

The entrepreneur utilizes knowledge in everything he does, creates knowledge over time, and imparts it in others. Entrepreneurs knowingly or unknowingly use existing knowledge, and improve on it. The knowledge is consistently built on and shared, and it progresses over time.

Aspects of knowledge creation include: 1) entry conditions, 2) base knowledge, 3) detail, 4) experience, 5) business context, 6) value, 7) starting point, 8) competitive advantage, 9) competency, and 10) collaboration.

Table 4. Knowledge creation: Entry conditions and barriers, base knowledge, level of detail, experience and expertise, and business context.

\section{Entry conditions and barriers}

The entrepreneur needs a basic level of competitiveness, technology and skill. This constitutes and implies a basic level of knowledge.

A certain level of knowledge is required to: 1) recognize issues, problems, and opportunities, 2) use, interpret and synthesize knowledge, 3) create knowledge.

Businesses require diverse and high levels of knowledge and skill.

\section{Base knowledge}

The entrepreneur must build an adequate body of knowledge that he builds on and draws from, that is accurate, relevant, up to date, reliable, authentic and unique.

The entrepreneur needs a certain level of knowledge simply to be and remain relevant.

The entrepreneur must overcome the minimum knowledge barrier. He has to acquire and build up knowledge, until it is sufficiently exclusive and original.

To obtain a knowledge base or foothold, the entrepreneur may either build on extensive personal, direct experience (tacit knowledge) in a subject, or source it through an "open" source. An university may be approached to outsource research on a subject to, or perhaps to very quickly gather explicit knowledge on a subject.

\section{Level of detail}

The distinction is made between business knowledge and technical knowledge.

It is sufficient for the entrepreneur to study basic functioning and operation, and build business concepts around this. The entrepreneur does not have to go too much into detail, like technical detail.

Only the level, degree or amount of knowledge required to build a business case, concept, and model is required.

\section{Experience and expertise}

A lot of knowledge, ideas and opportunities come through experience and expertise.

Expertise generally transitions along the steps of: 1) developing a holistic industry understanding; 2) focusing on specific areas; 3 ) creating in-depth knowledge on a product or solution that the entrepreneur wants to take to the market.

\section{Business context}

There are basic fundamentals and principles of business the entrepreneur must get right.

New knowledge cultivated must substantiate and support the business concept, and have business sense.

New knowledge is drawn into a business concept, and a business concept is built around new knowledge.

Table 5. Knowledge creation: value. 
It is first and foremost about the business case and adding value.

Clear value proposition should be tied to knowledge creation. A goal, vision or direction should be tied to knowledge creation.

It is less a problem of knowledge creation, and more a problem of knowledge application. There is not really a shortage of knowledge creation. Rather, the issue is creating knowledge that has value.

It is much about understanding how new or even existing knowledge can be integrated into new business concepts or models. It is not so much access to knowledge, but the way - how efficient - knowledge is consumed.

The entrepreneur is interested in the benefits and potential that can be unlocked through certain, new knowledge - its application and potential in this regard.

The cost and benefit of an opportunity are assessed - the benefit or potential of the opportunity, and the likely cost in developing it. Opportunities are weighed up against their resource and system requirements. The potential of the opportunity is considered, as well as the cost of obtaining the knowledge required to realize it.

The value of knowledge is impacted by at least 2 factors: quality and uniqueness. The quality of knowledge entails how accurate, credible, and reliable the knowledge is. The newness or uniqueness of the knowledge entails how new the knowledge is, the extent to which the knowledge has been applied, the extent to which the value of the knowledge has been exploited, and the extent to which the knowledge has been handled and interpreted, and its opportunity has been exploited.

The uniqueness of knowledge may not be immediately apparent or predetermined.

The value of knowledge can be assessed, particularly based on relevance and application.

The value of knowledge is fluid and relative - changing.

The economy and cost of knowledge are considered. The objective is to get as much knowledge of good quality, at the lowest possible cost. Due to vastness, the opportunity cost of knowledge that is freely available should also be considered.

The value of knowledge also depends on the person accessing it. It is not always that the knowledge or information is hidden. The entrepreneur may not recognize the knowledge or information, or the value thereof, in front of him.

Table 6. Knowledge creation: starting point.

\begin{tabular}{l} 
Starting point \\
\hline Entrepreneurship is not linear - it does not follow a linear process. It is much about acting (taking action, doing), and \\
identifying the next step necessary to move an idea or opportunity forward. \\
The entrepreneur may start with opportunities as more (very) tacit knowledge, and then add more knowledge to it. He \\
must close any gaps in his knowledge to complete the picture. \\
Existing as well as new knowledge and information, events, etc, trigger questions and curiosity, that leads to further \\
inquiry. \\
Investigating how others have tried to solve a particular problem before, and how and why they failed. \\
The entrepreneur may possess inside or exclusive information or knowledge regarding some business process or supply \\
chain. \\
The entrepreneur can think along the lines of making things better and more efficient, etc. He may take an existing \\
business process or supply chain and note where and how it can be improved and made more efficient. \\
The entrepreneur may look to informal solutions that already exist, that he is or will be indirectly competing against. \\
The entrepreneur may continue on intuition - hunches - and looking deeper into these and such. \\
He may switch between analytical and holistic thinking, and change the level of perspective - focusing on a close-up, \\
or seeing the holistic or complete picture. \\
He may consciously and purposefully seek to counter fragmental thinking, and to broaden thinking. \\
Foresight and forecasting - anticipating possible futures - also builds knowledge. \\
Imagination equally plays a role in knowledge creation, transfer and application. \\
The entrepreneur may simply look to push limitations or boundaries. \\
In focusing on the potential or value in creating new knowledge, the entrepreneur may focus on areas which are \\
unexplored, or under-explored. It helps to know the relevance of an issue or object as opportunity, and the associated \\
knowledge gap - knowing to what extent it is understood.
\end{tabular}

Table 7. Knowledge creation: competency and competitive advantage.

\begin{tabular}{|l|}
\hline \multicolumn{1}{|c|}{ Competency and competitive advantage } \\
\hline Entrepreneurs may have varying ability to convert and translate knowledge into value. \\
Building a body of knowledge that becomes exclusive and unique. \\
Curiosity as a core competency. \\
Knowledge specific to creativity and ideas. \\
Knowledge specific to implementing opportunities. \\
The ability to readily contextualize and interpret knowledge and information in terms of implementation and application. \\
Implementation as core competency (even and especially in the context of knowledge creation). \\
\hline
\end{tabular}


Prototyping and learning. The ability to quickly create knowledge.

Thinking:

- Breaking from certain types of thinking - analytical or programmed thinking - and functioning in set routines.

- Focusing not on what you know, but what you don't know.

- Switching from more analytical thinking to more intuitive thinking.

- The ability to differentiate, discern, analyze, assess and evaluate.

- The ability to synthesize information and knowledge into new knowledge, or higher levels of knowledge.

- Zooming in and zooming out, and looking at knowledge and knowledge gaps at different levels - the basic fundamentals of how things function, and also how things integrate and form a whole.

Over and above other knowledge requirements, an opportunity may require certain skills. Skill sets can be seen as a particular type of knowledge - the tacit knowledge required. For this reason, skill sets may be as important.

The entrepreneur learns his strengths and weaknesses, and his true interests, and thus how and where he will be able to best add value.

Table 8. Knowledge creation: collaboration.

Collaboration
Projects or opportunities may be too big for the entrepreneur to handle on his own. It is no longer possible or practical
to contain all the knowledge pertaining to a product in a single individual. The development of a new product or system
requires combined knowledge, and is achieved through collaboration.
In the early phases of entrepreneurship, the individual relies on himself to acquire knowledge, but with time realizes the
benefit in collaboration.
The entrepreneur may be reluctant to share knowledge of his opportunity with others, and may want to work on the
opportunity all by himself, to protect his opportunity. But this can constrain and slow down the opportunity, because it
cuts out valuable help and feedback. Rather, the entrepreneur must learn techniques to share on his opportunity, without
compromising it.
The entrepreneur may both work independently, and work with a team. The entrepreneur may choose to first work on
his own, until he is ready to collaborate.
Through hierarchy, the entrepreneur can control how much he shares with whom, and the type of feedback he expects.
With hierarchy, ownership remains with the entrepreneur.
A group of experts that combine their knowledge can be very powerful.
Teams have greater capacity, task variety, and experience. Teams mix types of knowledge, and achieve greater balance
between explicit and tacit knowledge. A team brings more experience and different knowledge sources to the table. The
team members complement each other. (Even) if he works alone, the entrepreneur must find an optimal team to consult.
Team size is in proportion to the phase of the project.
Approaching more experienced, like-minded people, particularly in certain areas, and bringing together and
amalgamating knowledge across people and experts.
Knowledge is normally stored with a few experts. Specific skills can be incorporated to achieve specific goals.
Virtual teams are expert teams that are located around the world, and can speed up the process of development.
Connecting resources and experts, and integrating and bringing together knowledge.
It is possible to outsource knowledge creation - for instance, to buy knowledge.

Table 8. Knowledge creation: miscellaneous.

Miscellaneous
The entrepreneur has more knowledge than what he can consume. So it rather becomes a question of what to consume.
The entrepreneur should focus his effort and attention. It is better for the entrepreneur to go simple, than complex.
The objective of the entrepreneur matters - the company he wishes to build and the market or industry he wants to
operate in. This determines the entry level technology or knowledge required.
The entrepreneur should get to market (into the market) as quickly as possible, as cheaply as possible.
The entrepreneur should be tenacious about opportunities and ideas, and peruse them with might.
The quality of the opportunity may be improved by the quality of the knowledge.
Patents can help to ensure or extend exclusivity, but patents are not ideal, and have issues too.

\subsubsection{Knowledge Synthesis}

A lot of knowledge integration and synthesis occurs. Higher levels of knowledge are generated from lower levels of knowledge. A lot of knowledge bridging, application, and extension are also required, and also take place. For instance, bridging the academic and commercial divide. Books are a typical source of lower levels of knowledge.

Knowledge synthesis is closely associated with knowledge creation. Knowledge synthesis also readily 
points out the pace, speed and scope of knowledge accumulation and generation. For example, through a book, a person can acquire, consume, and process knowledge that took someone a lifetime to gain and build up. Furthermore, it is subsequently possible to synthesize the knowledge of a number of books.

New knowledge is created by existing knowledge and application. Any application - experience - as well as knowledge application, automatically create new knowledge that can and should again be reinterpreted and repackaged. New knowledge and information is reinterpreted against and married with the entrepreneur's existing knowledge.

Generating higher levels of knowledge can take time, and generally requires the right people, as well as creating the right culture. It is a continuous process that benefits from heavily investing in it. It is goal driven. Technology is utilized and relied on more, to synthesize and integrate knowledge, and to create new knowledge faster.

Table 9. Knowledge synthesis method.

\begin{tabular}{|l|l|}
\hline $\begin{array}{l}\text { Creating knowledge communities, and knowledge specialists or } \\
\text { champions. }\end{array}$ & Assigning responsibility. \\
\hline $\begin{array}{l}\text { Using KPIs (Key performance indicators). Focus on inefficiencies, } \\
\text { and customer satisfaction. }\end{array}$ & Benchmarking against leaders. \\
\hline Incorporating the latest knowledge. & Disseminating knowledge through the company. \\
\hline Putting together pieces of knowledge. & Incorporating diverse knowledge sources. \\
\hline Building customer knowledge. & Using innovation and creativity. \\
\hline $\begin{array}{l}\text { Understanding and interpreting the market. Identifying direction, } \\
\text { development trends, and weak signals. }\end{array}$ & $\begin{array}{l}\text { Analysis. Empirical, field work. Practical work - } \\
\text { trials and experimentation. }\end{array}$ \\
\hline $\begin{array}{l}\text { Reviewing past requirements and decisions that became orthodox, } \\
\text { but that are no longer grounded or substantiated. }\end{array}$ & Tenacity. \\
\hline
\end{tabular}

Table 10. Knowledge sources typically synthesized.

\begin{tabular}{|l|l|}
\hline (Expertise of) experts. & Research. \\
\hline Internet. & Experience through peers and networks. \\
\hline Statistics and related applied research. & Market research. \\
\hline Reading. & Quick formal training or education. \\
\hline
\end{tabular}

\subsubsection{Knowledge Reuse}

Reusing knowledge requires that the concepts of that which is borrowed, are transferred to, and reinterpreted for the particular destination or target industry first.

Knowledge reuse (KR) forms part of the competitive landscape. Borrowing knowledge also relates to best practice. It is also possible to speak of innovation in the context of best practice and progress. Each innovation raises the bar in terms of best practice. The entrepreneur must stay up to date. The knowledge behind competitive advantage or process improvement surfaces sooner or later.

Borrowing knowledge still serves as a way to innovate and solve problems, as it can suggest a lot of opportunities and solutions, and it enables and serves as a catalyst for learning. The underlying shift in environment or context that occurs when referencing another source, like another industry, surfaces a lot of knowledge. It also introduces a lot of challenges, because a lot is new, and because of limited available frames of reference.

Borrowing knowledge can also be via borrowing opportunities: realizing or understanding opportunities in other contexts, like other industries, why an opportunity works in another context, and why it constitutes an opportunity.

The entrepreneur can build on and advance the work of others, particularly bigger players. Opportunities generally grow with solutions, they don't necessarily diminish. Large organizations have a huge supply of expert knowledge sources, from multiple disciplines. Leveraging on that existing knowledge can be extremely beneficial.

KR may still be difficult, and may take time and resources. The knowledge must still be sourced, sought, reinterpreted, and reapplied. Knowledge that can be reused must be discovered and understood first. It must be determined how and to what extent knowledge, or the application thereof, can be applied to the entrepreneur's context. It may be necessary to use multiple references (sources), not just one. The value of or 
in reusing the knowledge must be established. The knowledge that can be borrowed, may not be that readily accessible or apparent. Also, the knowledge may be protected or withhold. The knowledge may also be very tacit. Borrowing knowledge may still involve and require extensive learning.

Factors that impact how quickly or readily knowledge can be borrowed, include: the extent by which the knowledge is protected by IP etc; and the complexity in the knowledge, and copying it. The reuse of knowledge may be made easier through technology.

Table 11. Typical knowledge reuse channels.

\begin{tabular}{|l|l|}
\hline Repackaging commercially successful products. & Borrowing from patents or other industries. \\
\hline Benchmarking. & Borrowing opportunities. \\
\hline Build on and advance the work of others. & \\
\hline
\end{tabular}

\subsubsection{The Relationship between Knowledge and Opportunity}

Knowledge forms the foundation of opportunities. Knowledge forms a prominent part of opportunities, and the language of opportunities. When contemplating, advancing, and discussing opportunities, their underlying knowledge and principles are accessed and referenced.

Two dominant views are that opportunity leads knowledge (or science), and its converse. Put differently, from the vantage point of knowledge, opportunity can emerge, or be pursued. The former implies knowledge leading opportunity: perusing knowledge, without really an idea or opportunity in mind. It entails not really knowing what to look for, until an idea is found. The belief is that knowledge may point out opportunity. The entrepreneur commences with perusing knowledge, without having yet identified an opportunity, and subsequently derives opportunity from perusing knowledge. The latter refers to opportunity leading knowledge: perusing knowledge, with a clear opportunity or idea in mind. Knowledge is sourced with an idea in mind, to advance it further. The entrepreneur commences from opportunity, and the resultant knowledge needs and requirements are determined by the opportunity.

Entrepreneurs recognize and fill knowledge gaps as they work on opportunities. The level of an opportunity greatly determines the extent of the knowledge gaps accompanying the opportunity. An opportunity may be believed to exist, but may not yet be practical. The entrepreneur may identify an opportunity, but the opportunity may still lack in terms of capability - the ability to be implemented. There may be a number of issues, concerns and problems that must still be overcome, before a practical solution is available. These may be relatively-abstract to highly-abstract opportunities. The entrepreneur must develop a good and holistic understanding of what he wishes to work on, including its functioning and intricacies. For certain opportunities, the entrepreneur may require expert knowledge.

Opportunity may lead to competitive advantage - being ahead. Knowledge can thus indirectly lead to competitive advantage. Knowledge and experience determine, enable, and unlock opportunity. The entrepreneur reduces the risk, and increases the quality and value of an opportunity through better knowledge. Knowledge intensive opportunities (KIO) and industries do exist.

Table 12. Comparison between opportunity-led knowledge and knowledge-led opportunities.

\begin{tabular}{|l|l|}
\hline \multicolumn{1}{|c|}{ Opportunity-led } & \multicolumn{1}{c|}{ Knowledge led } \\
\hline Clear idea in mind, for which knowledge is sourced. & $\begin{array}{l}\text { Perusing knowledge, without an opportunity or idea in } \\
\text { mind yet. }\end{array}$ \\
\hline The idea or opportunity precedes perusing knowledge. & $\begin{array}{l}\text { An idea or opportunity follows and is derived from } \\
\text { knowledge. }\end{array}$ \\
\hline $\begin{array}{l}\text { Knowledge is accessed to substantiate and support an idea } \\
\text { or opportunity. }\end{array}$ & Knowledge is accessed to suggest an idea or opportunity. \\
\hline $\begin{array}{l}\text { The entrepreneur has little difficulty to identify and } \\
\text { recognize an idea or opportunity. It is not necessary to first } \\
\text { source knowledge to identify an opportunity. }\end{array}$ & $\begin{array}{l}\text { Perusing knowledge helps the entrepreneur to identify an } \\
\text { idea or opportunity. }\end{array}$ \\
\hline A preference for the empirical, practical, or tacit. & An appreciation of explicit knowledge. \\
\hline
\end{tabular}

Table 13. Characteristics of knowledge intensive opportunities.

Most good opportunities are knowledge intensive. 
The knowledge intensity of opportunities are determined by factors like: scale, complexity, uncertainty, and originality.

There are a lot of points and aspects to consider as part of the opportunity.

As the scope, etc of an opportunity increases, so does its knowledge requirements, cost and risk.

KIO generally require and build on diverse fields with extensive depth in each - opportunities that require a team of experts.

KIO can be created by increasing the (knowledge) mix.

Depth of knowledge and scope of knowledge are characteristics of KIOs.

KIOs and their knowledge sources may be: 1) highly specialized, 2) very specific, 3) accurate, 4) implemented and verified, 5) practical, and 6) have very narrow focus.

KIO also may have additional barriers, like increased skills requirements, support and distribution.

With KIOs, it may be difficult to maintain a holistic view, and the tendency may be to rather focus on particular or isolated aspects.

Technology, like machine learning and AI, can be knowledge intensive, or can increase knowledge intensity.

Technology can increase and accelerate content and understanding.

Certain industries, like technology industries, are generally knowledge intensive.

\subsubsection{The Relationship between Knowledge and Creativity}

In general, the entrepreneur's knowledge enhances his creativity and his ability to identify opportunities. Conversely, the entrepreneur's creativity may contribute to his experience, and subsequently his knowledge.

Knowledge inspires thought and triggers creativity. Thus, integration of knowledge and generation of higher levels of knowledge, contribute to and open the door for creativity and innovation. It also leads to ideas regarding where knowledge gaps and opportunities are. Part of the purpose of education is to install the capacity to make distinction: Similarly, knowledge increases the capacity to differentiate within systems, particularly complex systems, and by extension, industries. It aids creativity, as creativity relates to the ability to see and create something new, or to enhance a highly specialized knowledge base. Knowledge of how something operates and functions, and having a broad understanding of a product, market or industry, will point out the opportunities for creativity - to be creative.

Creativity and being creative - then also intuitive thinking - spur a lot of opportunities and ideas. Still, creativity requires and benefits from a strong knowledge base. Getting a lot of input - reading, etc significantly contributes to ideas.

The innovator is distinct from the entrepreneur. The entrepreneur is predominantly concerned with value, not knowledge, science, technology, etc. Only certain knowledge really creates value. Truly valuable knowledge is driven or based on customer need.

\subsubsection{Knowledge Types}

The aspects of knowledge types involve: 1) typical characteristics, 2) vantage point, 3) scarcity, 4) access, 5) depth and scope, 6) relevance, and 7) collaboration. Specific knowledge types include: 1) tacit knowledge, 2) explicit knowledge, 3) experience, and 4) intuition.

Table 14. Characteristics of knowledge types.

\section{Characteristics}

The entrepreneur builds on existing knowledge, whether his own, or what he borrows from other contexts.

The entrepreneur makes use of a lot of industry specific knowledge.

The entrepreneur's knowledge requirements and thus his knowledge sources change with time.

Potentially new knowledge sources or bits must be validated.

\section{Vantage point}

The entrepreneur may start with empirical input (tacit knowledge), or explicit knowledge, and perhaps look to synthesize this into higher levels first. A question is to what extent tacit knowledge can be as readily synthesized into higher levels. Some entrepreneurs may like to start with opportunities as more tacit knowledge, and then add more knowledge to it. Even with limited expertise in a particular field, it may still be possible to capitalize on an opportunity. 


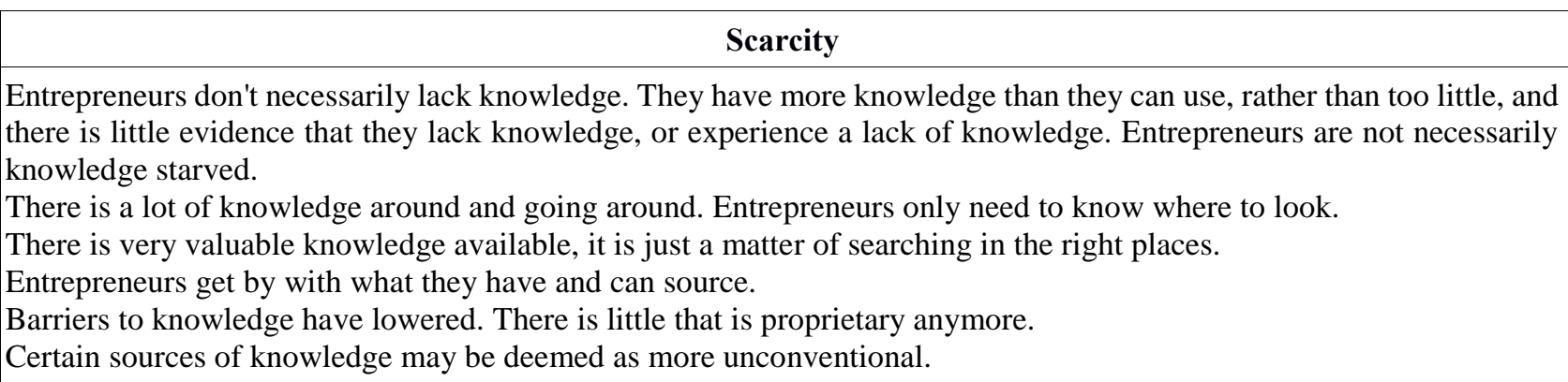

Table 15. Characteristics of knowledge types.

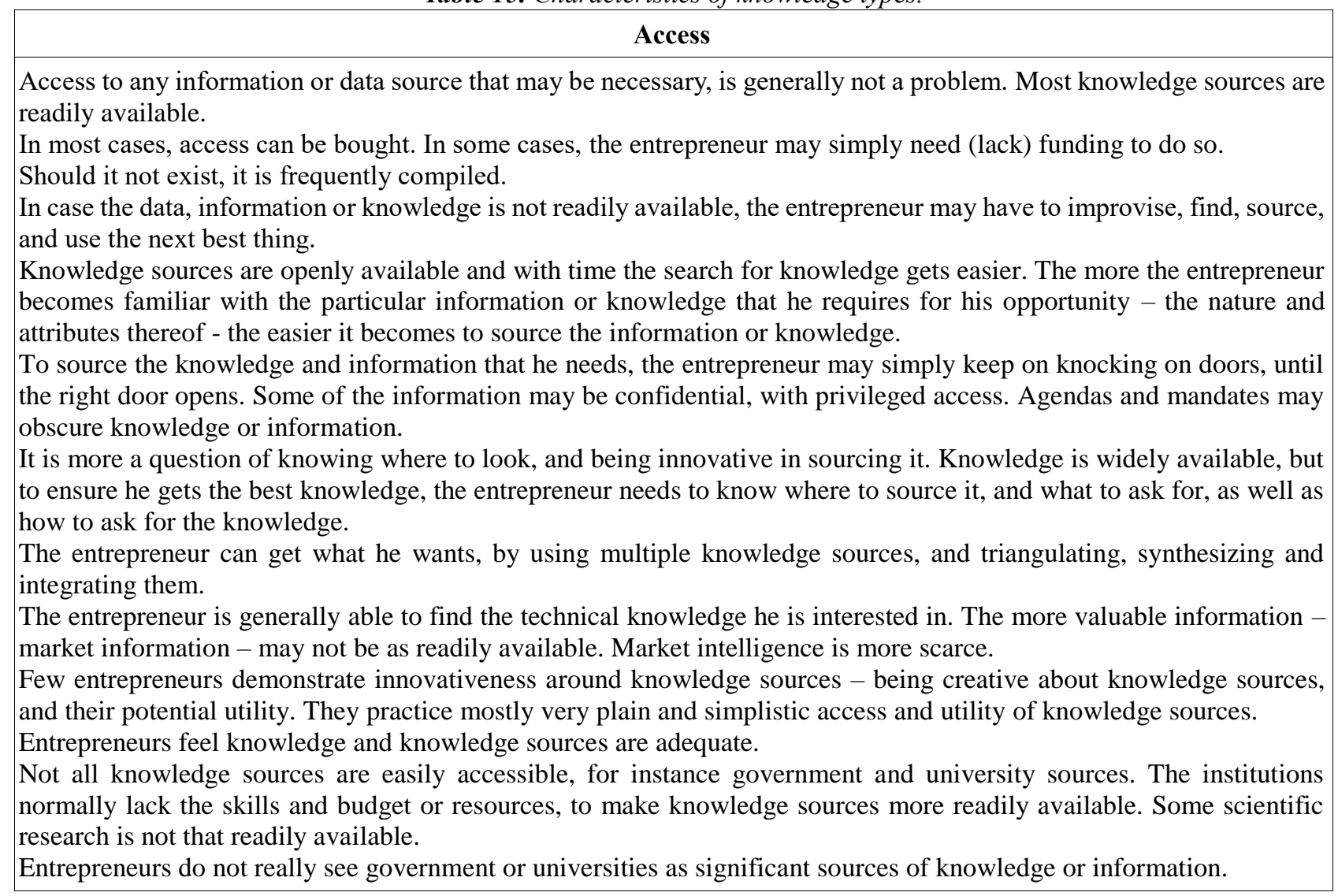

Table 16. Characteristics of knowledge types.

\begin{tabular}{|l|}
\hline \multicolumn{1}{|c|}{ Depth and scope } \\
\hline Entrepreneurs generally use a balanced portfolio of knowledge. All the types of knowledge are seen as relevant and have \\
a place or role. \\
A lot of knowledge integration takes place. The entrepreneur must resolve and integrate a number of different knowledge \\
sources, and get them to work together. \\
Few entrepreneurs are intimidated by different and certain knowledge sources. \\
The entrepreneur blends explicit and tacit knowledge. The entrepreneur generally builds on both (very) explicit \\
(scientific), and (very) tacit (applied or practical) knowledge sources. Entrepreneurs look at both science, as well as \\
practical problems and operations. Tacit and explicit knowledge generally complement each other. Knowledge gaps may \\
require both tacit and explicit knowledge to be filled. \\
Theoretical knowledge provides perspective, but practical knowledge provides very direct answers, details, insight and \\
practical know how. A combination of formal knowledge and tacit knowledge is thus necessary and used. \\
The entrepreneur may opt for and benefit from richer data sets. This may constitute more direct, continuous and real \\
time data sets, observation and data capturing. Or, having access to different data sets, and different vantage points, for \\
the same phenomenon. Also, observing the same phenomenon in new ways. \\
Time is a serious constraint. Most sources of information are available to the E, but time dictates the level of information \\
that can be extracted and obtained. Knowledge sources are increasing in richness. This can impact the E, in that it \\
becomes more demanding to work through knowledge sources.
\end{tabular}


Table 17. Characteristics of knowledge types.

\begin{tabular}{|c|}
\hline Relevance \\
\hline $\begin{array}{l}\text { Things like questions, concerns, etc., around events, trends and signals, may point to changes in the relevance of certain } \\
\text { knowledge - what may be or may become very relevant in the (near) future. } \\
\text { Knowledge is reinterpreted against the industry, to determine its practicality and relevance. } \\
\text { Knowledge should not simply be sophisticated or brand new, but practical and applicable. }\end{array}$ \\
\hline Collaboration \\
\hline $\begin{array}{l}\text { Collaboration is increasing, and collaboration distances are decreasing. } \\
\text { The entrepreneur lives in the network society. Barriers to collaboration are disappearing, and collaboration is both } \\
\text { worldwide, and increasing worldwide. } \\
\text { Knowledge and information flows have and continue to increase. } \\
\text { Technology is advancing collaboration, and collaboration is increasingly on the fly. }\end{array}$ \\
\hline
\end{tabular}

\section{Table 18. Specific knowledge types.}

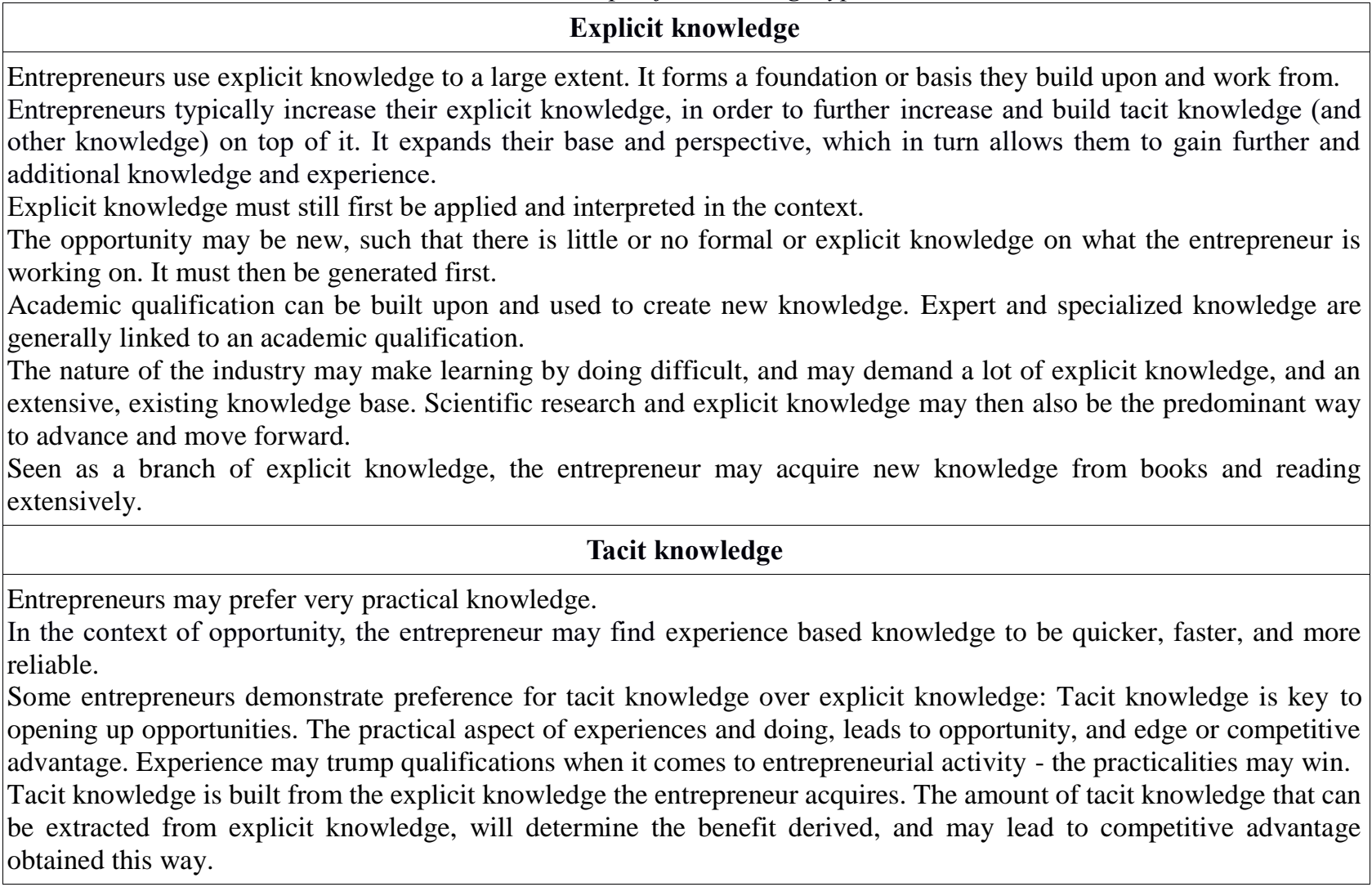

Table 19. Specific knowledge types.

\section{Experience/ experiential knowledge}

Experience is seen as a combination of both explicit or theoretical knowledge, and tacit or application knowledge. The entrepreneur may also extensively make use of experiential knowledge, as different and integrated forms of tacit and explicit knowledge - knowledge that is very contextual or practical, and interpreted for a particular case and context. Some entrepreneurs rely predominately on the practical (tacit) aspect of gaining knowledge. A lot of learning occurs by simply doing, and a lot of knowledge is consequently gained this way.

\section{Intuition}

The entrepreneur may make use of intuition for direction.

Opportunities and knowledge creation may stem from intuition, which is related to creativity and creative thinking. Intuition is prominent in creative thinking.

\subsubsection{Knowledge Sources}

Typical knowledge sources include: 1) customers, 2) conferences, 3) networks, 4) experts, 5) online resources, 6) context specific sources, 7) borrowing and benchmarking, 8) universities, 9) composite sources, 
Pillay, D. and Barnard, B., 2019. Entrepreneurship and Knowledge Management: Knowledge Requirements, Utility, Creation, and Competency. Expert Journal of Business and Management, 7(1), pp.44-81.

10) science and scientific research, and 11) entrepreneurship-specific statistics and information.

Table 20. Knowledge sources.

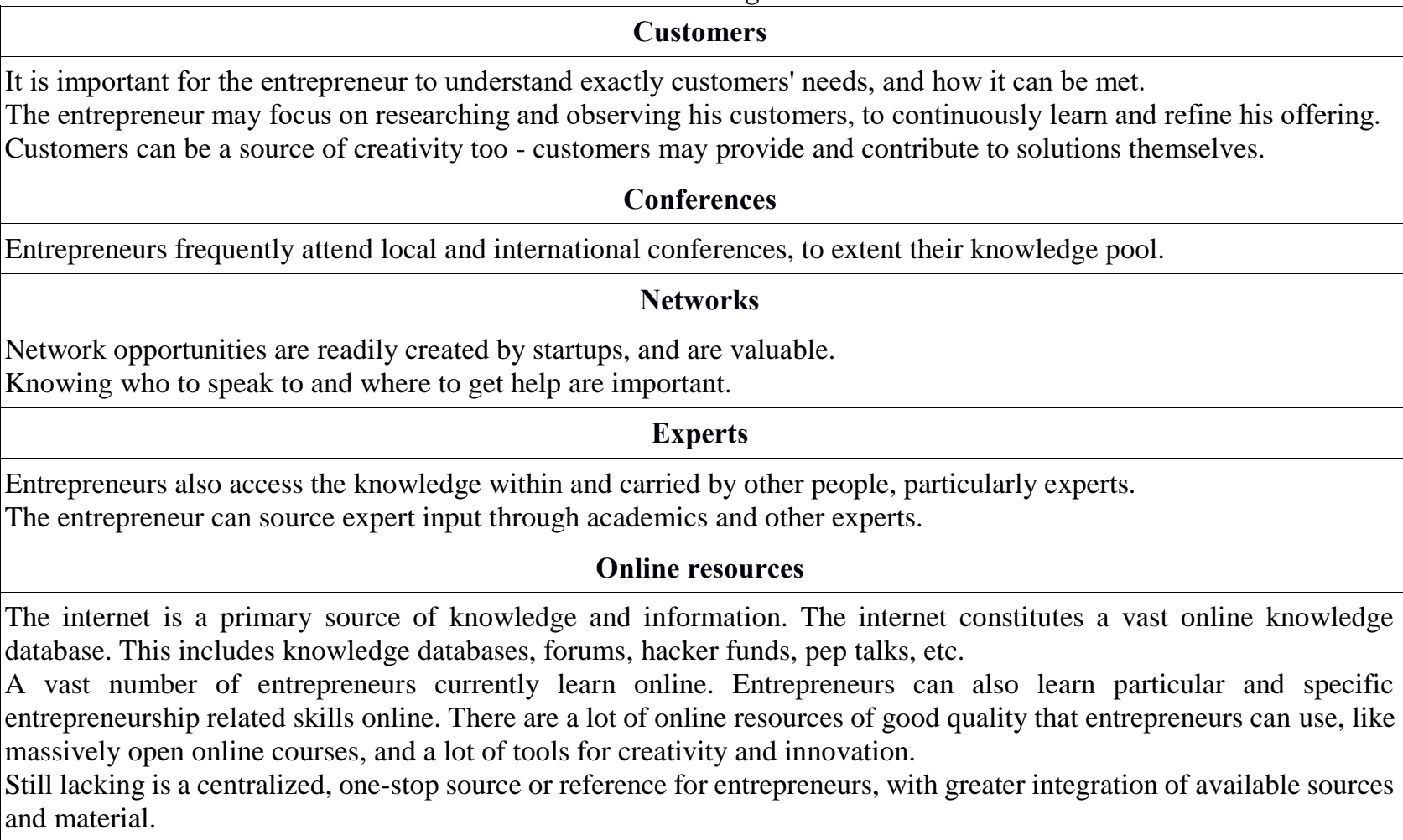

Table 21. Knowledge sources.

\section{Context specific}

There is some industry related knowledge as well, to develop and advance understanding of the industry.

\section{Borrowing and benchmarking}

Other people's work may be incorporated and built upon.

The entrepreneur may distill and extract knowledge within the field, for example from key players, their methods and solutions, and reinterpret it, to be further creative.

The knowledge and level of knowledge in the industry may be inquired, for example, by attending conferences.

\section{Universities}

Universities constitute great reservoirs of knowledge, and have great capacity to create knowledge.

This can also be knowledge the entrepreneur may need. Online courses make the knowledge of universities a lot more accessible.

\section{Composite sources}

Models help explain how things function and work, and incorporate various knowledge sources. Such understanding is key to develop new knowledge, and also emanates from the practically of just doing. It entails a combination of learning and doing. It extends and builds the knowledge base, and the understanding of the problem. It also offers evaluation of thought, and understanding of the problem, through empirical work. It puts explicit knowledge to practice, by applying it.

Table 22. Knowledge sources.

\section{Science and scientific research (SR)}

Scientific research provides understanding and other benefits.

Science and scientific research create the knowledge base and models of the world - the models used to explain and understand things. It forms the basis that innovation builds on.

Scientific research or knowledge can provide the entrepreneur with perspective, to resolve problems that he can't solve by himself. It can help with evaluation, assessment, and validation.

Very basic research can already provide perspective and background. This can reduce risk and save time. It may be absolutely essential in niche industries, to assist with understanding the problems better, and to aid in finding solutions. 
Academic and scientific research may be highly relevant in an emerging or new field.

Science and scientific research may provide perspective, but it does not necessarily help to better understand problems: The problem itself must still be primarily studied and understood. Scientific research and science must first be interpreted in and for the particular context, to be of true use.

\section{Basic research}

In certain cases, the entrepreneur requires and can make use of very basic scientific research, also because the problem or opportunity has such a nature. Otherwise, and in most cases, the entrepreneur rather utilizes and builds on very practical and applied research and knowledge.

\section{Applied research}

Entrepreneurs suggest more applied research. An example may be practical or applied research pertaining to innovation, like case studies. In that sense, having knowledge of best practices, as practiced by industry leaders.

Table 23. Knowledge sources.

\section{Entrepreneurship-specific statistics and information}

With certain information, entrepreneurs can strategize more.

Sources of knowledge that can speed up innovation may for example be error logs of companies (although perhaps very hypothetical), scientific research databases, and statistical databases.

Innovation and opportunities also constitute and stem from identifying problems and finding solutions to problems. Therefore, making available greater knowledge on problems.

Practically, entrepreneurs would benefit most from industry specific knowledge sources.

Specific information on entrepreneurship may itself be valuable, like a database of past opportunities, for instance opportunities that received funding in the past - detailed statistics and information around why certain opportunities failed or succeeded. It may be possible to discern need, gaps and opportunities from a database of entrepreneurs' past work, funding and opportunities.

It will be invaluable to better track entrepreneurs and what they are working on, as it can realize a lot of value creation. It can also improve benchmarking, and collaboration.

The knowledge entrepreneurs use, may generally be too new and thus fluid, to have specific or dedicated knowledge databases that the entrepreneurs can benefit from.

Important would be how the databases are structured and presented - whether they are easy to use, consume, and understand.

The depth and sophistication of these databases will be important.

Ownership, management, implementation, integrity, and quality of such databases, are also important considerations.

\subsubsection{Factors Inhibiting Knowledge Creation}

There is great similarity between the factors that limit or encourage innovation, and the factors that hinder or help knowledge creation. The value placed on creativity and innovation, as well as knowledge and knowledge generation, is crucial. The factors that inhibit knowledge creation, include: 1) resources and risk, 2) time, 3) culture, 4) focus, 5) collaboration, 6) systems, 7) national culture, 8) discipline, and 9) competition.

Table 24. Factors inhibiting knowledge creation.

\section{Resources and risk}

The availability of funding and finance.

Development - developing opportunities - is expensive. Knowledge creation may involve a lot of or extensive experiments and trial and error.

The attributes, particularly value, of knowledge may be obscure and difficult to assess.

Opportunities are not guaranteed and can fail.

Failure may not be an option for the entrepreneur.

The entrepreneur weighs up the cost (and benefit).

The entrepreneur does not necessarily have the resources to take big risks or challenges, or to take on big innovation projects.

Entrepreneurs may actually be risk averse. They may demonstrate varying levels of risk appetite or propensity. Propensity to take risk may impact the extent of new knowledge creation.

\section{Time}

Knowledge creation may be heavily constrained by time constraints and operational requirements. Entrepreneurs struggle to find time for knowledge creation.

\section{Culture}


The culture may not be conducive to knowledge and innovation. Freedom is required to experiment and learn. A lot of trial and error may be required, and this should be supported. Too many rules and regulation may also be restrictive. Organizational structures and design may restrict collaboration and inter-disciplinary work.

Knowledge transfer is hindered by the lack of communication between all levels of the business. Poorly implemented communication loops hinder knowledge flow and transfer. Knowledge is confined at the top. The knowledge of staff is not adequately valued and tapped. A lot of top-down communication occurs, with poor bottom-up communication.

\section{Table 25. Factors inhibiting knowledge creation.}

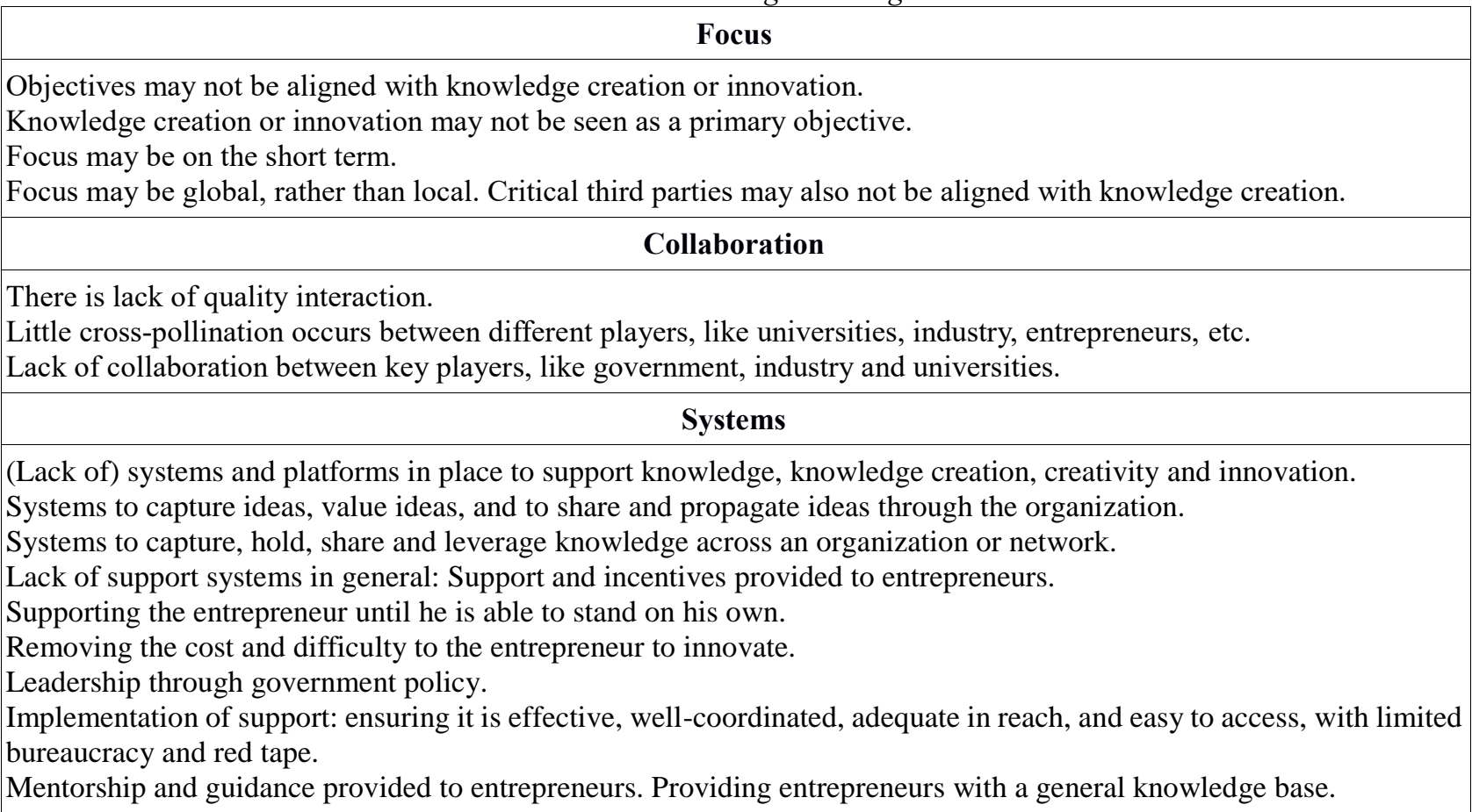

Table 26. Factors inhibiting knowledge creation.

Culture (societal, national)

Broader cultural, societal factors, and embedded culture may inhibit and limit creativity and innovation - what is seen and accepted as innovative.

Knowledge creation and application are affected by things like social dynamics, uncertainty, and risk appetite.

Certain things culture and society would oppose and see as taboo.

\section{Discipline}

There resides a lot of effort, sacrifice, and discipline in knowledge creation as part of entrepreneurship.

Proper culture is required for knowledge creation and transfer.

The entrepreneur should stay relevant.

Entrepreneurs are not doing enough homework and conceptual work. They are not adequately backing up and substantiating their ideas, assumptions, and opinions with information and knowledge.

\section{Competition}

Lack of incentives and motivation: there exists a lot of variety and competition in global markets, and it is relatively easy to reverse engineer products. This steals motivation to champion the development of radically new technology, rather than merely committing to incremental innovation.

The entrepreneur must decide whether it is best to be the first mover or second mover. It depends on whether there is possibility to disrupt the market. The first mover must create and figure out markets, and others may steal this. In markets or industries where resources or capacity are sunk, it may pay to be the first mover.

\section{Other}

Lack of training.

Lack of appropriate incentives.

Infrastructure, like internet and ICT (information and communication technology) infrastructure, may still hinder access to knowledge. 


\subsubsection{Culture}

Knowledge is situated in culture and institutions. The impact of culture is apparent, when stepping in and out of group, organizational or national contexts. Furthermore, the entrepreneur builds a business, more than a product. The business entails systems, processes, and culture.

\section{Innovation culture}

Culture and innovation culture impact knowledge use, generation, sharing and management. Culture also determines how knowledge is internalized and utilized, and how value is added to knowledge - how higher levels of knowledge are created. Culture is created, defined, and sustained by individuals' ability to think, create and utilize knowledge. An important indicator is how serious innovation is taken. Something like knowledge sharing cannot be enforced or legislated. It must be out of free will, and it is determined by the culture. Proper culture implies lifetime or continuous learning. Depth of innovation also impacts what is incorporated into innovation.

\section{Corporate culture}

Corporate culture equally determines how knowledge is created, and what knowledge is created. Corporate culture impacts an individual's ability to utilize knowledge and think creatively. The corporate culture may be conducive and supportive, or constraining, with regards to innovation and knowledge. The type of corporate culture (supportive or hindering) determines and impacts future growth and strategy. Knowledge is embedded in and pertains to the business, not just a product. Culture may also be more observable in implementation, as opposed to design, planning or creative thinking.

\section{National culture}

Cultures introduce a particular perspective, vantage point, approach, and speciality. Each culture has its benefits and disadvantages. Culture is embedded or entrenched. Culture is engrained in and part of thinking and reasoning.

Social factors and setup may determine whether a culture is innovative, creative, inquisitive, and tenacious. Societal factors affect innovation and entrepreneurship, by shaping and impacting ambition, selfimage, and self-confidence. Culture sets and impacts outlook, way of doing things, norms and values - what is valued, and what not. Furthermore, there may be political barriers to entrepreneurship.

The moment other cultures are encountered, own culture is recognized, and it is possible to step outside of its boundaries. The entrepreneur would benefit from developing a cultural sensitivity in terms of knowing and realizing how culture is affecting perspective and vantage point.

Table 27. Culture and knowledge creation.

\section{Innovation culture}

A culture conducive to innovation and knowledge.

Recognizing the value and application of knowledge.

Establishing a culture and environment that derive value from knowledge and that exploit knowledge.

Allowing freedom to experiment and to learn.

\section{Corporate culture}

Organizational design. Silo mentality is a classical case and example: grouping employees according to function and in set, conventional or orthodox ways.

Freedom and empowerment. The extent by which people are empowered to innovate in their roles.

Leadership support and buy-in. The extent by which higher level people, like directors, adequately understand innovation and knowledge.

General support and buy in. The extent of support programs and resources for innovation and knowledge. The extent by which peripheral services are developed around knowledge centers.

\section{National culture}

Cultural sensitivity in terms of knowing and realizing how culture is affecting perspective, vantage point, way of doing things, norms and values.

Stepping outside of cultural boundaries.

\subsubsection{Technology}

Data mining and big data

Data Mining (DM) or Big Data (BD) raise the competitiveness and competency bar. It proposes new requirements to compete and remain competitive, new levels at which opportunities are created, as well as new levels of knowledge required and incorporated into opportunities.

Data mining is not highly scientific in method. It is more to provide insight or perspective. It does not 
follow rigorous scientific method. It is not altogether guaranteed or proven to be objective.

Entrepreneurs can build on the data mining and big data that large organizations deliver and produce.

Table 28. Impact of big data and data mining on knowledge creation.

DM and BD increase the amount of data involved and incorporated. DM and BD promise an extensive amount of opportunities, due to the amount of knowledge that is and can be created this way.

DM and BD can increase the accuracy and comprehensiveness of knowledge and understanding, thereby permitting better and faster decisions.

It helps to understand customers, customer needs, customer behaviour, and markets better, and allows mass customization.

BD can further help to visualize, explain and make sense of data, extract information and thus knowledge from available data sets, and synthesize knowledge to higher levels, and in this way suggest solutions, innovations, and further opportunities.

$\mathrm{DM}$ and $\mathrm{BD}$ allow and increase the extraction of useful information from data.

It implies and offers integration of knowledge, and development of higher order knowledge.

$\mathrm{BD}$ and DM can substantiate a lot of thinking and views.

$\mathrm{DM}$ and $\mathrm{BD}$ have an underlying creativity or innovation component, and may help to suggest opportunities. DM and BD shape opportunities, and assist with finding solutions.

$\mathrm{DM}$ and $\mathrm{BD}$ are to change and revolutionize how we do things. It is set to change how we think and what we know, when.

DM and BD can help to solve very practical problems.

\subsubsection{The Environment}

The systems in a country can and should be considered in the context of the level of entrepreneurship, as well as the level of knowledge and knowledge creation, they can and cannot support. The extent by which the overall culture is entrepreneurial has a great impact, and can be a major enabler.

The impact of the education system, labour markets, and universities on the practice of entrepreneurship, is much influenced by the environment, and the type or nature of entrepreneurship practiced - to what extent these and such inputs are deemed crucial.

The entrepreneurship system or eco-system may wish to circumvent inefficiencies and challenges it faces. It will try to work around it. Hypothetically, the entrepreneur can circumvent any market imperfection, including labour and education, and work around it. For example, he can source the necessary skills from abroad. The entrepreneur generally finds a way. The entrepreneur is predominantly self-sufficient, and defaults to taking control and taking charge of situations and circumstances, to ensure success. Hard work and application of common sense will equally pay off. Still, there may be practical issues.

There are challenges and gaps in and around labour and education that affect entrepreneurship. The quality of labour and education negatively impacts entrepreneurship, in that, in many cases, entrepreneurs and business must bridge and overcome gaps ascribable to education and labour.

\section{Education}

In general, people are losing the ability to think, and in this sense are becoming lazy. The ability to solve problems, and to think for oneself, are crucial. Critical thinking is extremely important for an entrepreneur.

(Hypothetically,) only the higher levels of education - mainly tertiary education - truly develop the ability to create knowledge, and to think originally. At lower levels, it is mostly about learning and accumulating basic knowledge. Lower levels also offer less freedom in terms of thinking.

Entrepreneurs can learn independent thinking and self-organization, that is crucial for entrepreneurship, outside of universities, and that is why they don't necessarily focus on education, or frequently drop out. Entrepreneurs are essentially independent thinkers who set their own goals and find their own direction. In this regard, the education system can be inhibiting to entrepreneur, because they do not necessarily foster or encourage such levels of autonomy.

The education system is not truly developing people. Academic institutions do not teach critical thinking, and critical thinking skills are lacking. The education system should develop a person's capacity to distinguish - make distinctions - in his world. Universities (education) are not teaching innovation - how to be innovative. Education is merely taking and putting people through the system. The education system may also be inhibiting creativity and innovation, because it is stereotypical in thinking, with run of the mill, and 
one size fits all mentalities. A drought in technology creation and innovation may currently be experienced, likely due to the quality of education.

Education should provide the means to build a foundation that can be leveraged. The student should be prepared to (be able to) get a job, to further his experience and expertise, to provide him with an industry and a context where he can gather tacit knowledge, so that he becomes self-sufficient and ventures on his own. The education system should provide a foundation that can be built on, and that allows and opens opportunities to enter the job market.

If education focuses on teaching that ensures students are adequately equipped with regards to knowledge and application, this will result in students being innovative and finding better ways of doing things.

The education system is still focused on occupations. Education may be too formal and structured. Entrepreneurship is more practice than theory, and more entrepreneurship is necessary. In this sense the education system is outdated. More practical education than theoretical education is required. Education should develop and build the entrepreneur's knowledge base and skills base.

Entrepreneurship education is poor. Also, it is already poor, lacking, or even non-existent, at school level. It is difficult to teach entrepreneurship, as it is something that is learned through experience and exposure. Also, the intention should be to not force entrepreneurship onto people who are not really interested in being entrepreneurs. The educational system is flawed, by not introducing entrepreneurship into the curriculum. Early (practical) exposure to entrepreneurship is required, and not the traditional knowledge based approach (formal and structured).

Universities may not be as practical and relevant as they used to be. Universities do not necessarily produce labour aligned to entrepreneurship and high technology. University programs are too long, and focus on the wrong outputs. They should rather offer a lot more short courses that are outputs based. Online education is emerging. E-Learning and online courses are becoming more formal, and offer a number of short courses. The objective should be to train people skills in demand by corporations, faster. This may entail shorter education cycles. Shorter courses may be a lot more practical and aligned to work conditions and requirements.

Certain industries and functions require (people with) very specific knowledge.

\section{Labour}

Labour markets provide little security and support to entrepreneur. Labour is making entrepreneurship more challenging. Human resources are under-valued and under-emphasized, and thus under-developed.

The labour market also determines the opportunities available to the entrepreneur, particularly when he sets off, and also influences and impacts his development. It determines the skills the entrepreneur will and can develop. It can influence his path and destination - where he ends - and how quickly he gets there. The labour market determines the more difficult skills, like soft skills, the entrepreneur will acquire, as well as his specialization.

The labour market may also be relatively under-developed, with little existing relevant expertise, such that the entrepreneur may have to find a lot of solutions and solve a lot of problems - find his way - a lot, and do so by himself. Experience is seen as more important than explicit knowledge by some.

The labour market does not promote knowledge sharing, development and transfer of knowledge. The development and transfer of knowledge occur through collaboration between and with others.

Corporate culture is generally restrictive. A divide exists between top management and the lower levels. Corporations instill a silo mentality, which does not promote creativity and innovation. Job functions are siloed. Development of knowledge, or moving too much outside of functional roles, are not encouraged. Knowledge is not necessarily valued. Very little empowerment of people occurs. Very little encouragement, recognition and reward, and incentivizing of good and also entrepreneurial behaviour, occur. Entrepreneurship may even be inhibited, particularly when maintaining the status quo is favoured.

Labour is generally expensive, and suffers from productivity issues. The labour market is very expensive and not very productive, which hinders and makes entrepreneurship difficult. It is difficult to keep people motivated. Discipline, work ethic and culture are lacking. Work discipline, ethic, and culture are an international phenomenon.

The relationship or progression between technology and productivity is not or has not really been linear. Productivity did not necessarily keep with technology. People are not ready for jobs - to work. As employees, people bring little to the table - they add little value. They must be trained and dusted off - prepared and groomed - first, before they can be really productive in their work. The entrepreneur may find the labour market as not very productive throughout the world. Both government and private sector fall into this category. Therefore, it is difficult for an entrepreneur to impart knowledge to an employee. The employee should possess an unique skill that enhances the entrepreneur. It is difficult to source talent and employ the right people, that will actually contribute to the entrepreneur and to his business. There is a shortage of skilled labour. It is 
difficult to find skilled human resources, particularly in cutting edge or emerging technology.

Issues around labour regulation are also complicating matters for the entrepreneur. The introduction of automation is changing the labour market.

\section{Universities}

Different types of IP exist. Universities may have less commercial focus, and thus alignment. They may lack in this regard, and may be more focused on research, academic programs, and merit. Their focus may not be on the end result, but rather on short term goals - pushing numbers. This has a negative effect, as the research published is taken to be of poor quality and little value.

Very few university projects have underlying IP potential that can be patented, and thus have business opportunity. Universities predominantly focus on publishing their research, which can actually further reduce the business opportunity potential. In some ways, and in some instances, universities patent (their) work, thinking and hoping that someone will pick it up and run with it. This is not necessarily an optimal approach.

\subsubsection{Knowledge of Typical Problems}

Some entrepreneurs are very aware of problems within his environment, others are not as aware of the pressing needs and issues.

One view is that the entrepreneur is mostly preoccupied with his own work. It takes effort to really know and understand an opportunity or problem, to the extent that the entrepreneur can advance it. Because of this, the entrepreneur may be selective and confined to his own work. The entrepreneur may be predominantly focusing on, and preoccupied with, the opportunity he is working on, and as a result may be less interested in other opportunities or problems around him.

The contrary view is that the entrepreneur by default looks for opportunities or problems to solve, rather than just solutions. Science, technology and innovation are much about application. Consequently, the focus is constantly on finding application for science, technology and solutions. The implication and consequence are that the entrepreneur is very aware of general, societal, and other problems. A true innovator or entrepreneur will also constantly think of solutions to new problems he comes across. The entrepreneur constantly considers and assesses problems, opportunities, solutions, knowledge and new knowledge, resources, developments, etc.

The entrepreneur is normally very connected, and outgoing, or up to date, in terms of what is going on. To a large extent, the entrepreneur can stay abreast through simple means, like conversations.

Table 29. Knowledge of typical problems.

\section{Organizations}

It is not readily known or discernible what companies are working on. They try to protect this knowledge, but it can be predicted or speculated. Information that can help with this, is new patents registered, and new recruiting of skills - new skill sets sought by a company.

\section{Society}

Science always offers and helps with perspective, perspective formation, thinking, and making sense of phenomena. The prevalent research topics being worked on can form a good indication of the pressing issues.

Table 30. Issues around typical problems.

Having naive or shallow perceptions or understanding of problems, leads to coming up with naive and shallow solutions. It may take effort to get to the core of a problem or matter.

To really know what communities and organizations struggle with, or the problems they face, it may be best to experience it first-hand. It requires engaging with the community or organization, and positioning or placing yourself within the community or organization.

The organization or representative may find it difficult to express their problems and difficulties. (The problems and difficulties must best be experienced first-hand.)

Knowledge sharing:

In general, there are too little information and knowledge sharing, dissemination of knowledge, and creation of awareness, or simply reaching out - creating momentum, support, and groups around and behind issues, problems, ideas, etc. - that take place.

Using technology to improve sharing and awareness. Technology can be used to speed up dissemination of scientific research, and to make it more accessible, easier to find, and more prominent. Technology and the internet are not yet fully exploited, when it comes to knowledge sharing and dissemination. 
Social collaboration - collaboration through social platforms and the use of technology.

Implementation:

Organizations, institutions, etc., typically do not face scientific problems, but more practical problems, that may perhaps also be described as engineering problems. It is thus rather perceived as an issue of proper implementation of existing knowledge.

Understanding problems from a scientific perspective may not always be relevant. It is not the only way to understand problems and to learn about problems. Problems still require implementation, and practical implementation may be as much a part of the problem. Scientific research does not necessarily resolve the implementation hurdle.

There is not necessarily a shortage of scientific research pertaining to typical problems, and to be able to advance typical problems. There is plenty of scientific research out there to solve typical problems. The issue is rather the execution or implementation that fails.

\subsubsection{Future Direction and Opportunity}

Emerging technology has a lot of potential to introduce innovation, but few entrepreneurs are looking at emerging technology. Entrepreneurs are more focused on basic problems and basic needs. Entrepreneurs should also move away from more immediate problems to "new" problems - more work that can be described as emerging fields, etc.

Innovation, optimization, and more efficient products are still possible in even mature and commoditized markets. The focus should be on continuously looking for and identifying new business models, and continuously optimizing business models. A lot of shifting the boundaries out in terms of what is deemed as possible, should take place.

Applied research can benefit all fields and markets, and all entrepreneurs.

There is opportunity in very local problems. Contextualized knowledge always has greater value. Therefore, knowing and understanding the local context. Science and scientific research can be extremely beneficial for local and domestic problems. Research and knowledge development can focus or concentrate on key local problems, such as poverty, unemployment, food security, etc. Universities may focus on finding practical applications for science, or applying science in new ways, with practical applications and problems in mind.

Research can help to improve the environment of entrepreneurship. It can help with further development of entrepreneurs themselves. It can improve the quality of entrepreneurship. It can improve the quality of entrepreneurship support services.

The problems, dilemmas, shortcomings, and disadvantages of importing or borrowing ideas, and not developing or creating enough research and knowledge self, should be kept in mind. Indigenous, tacit knowledge that is derived from a lot of experience, should be incorporated and built on more. Platforms can be further developed, to incorporate indigenous knowledge, and formalize it more. Local knowledge can be developed more, to support businesses, and to implement and apply, ideas, science and knowledge.

4.2 How do entrepreneurs perceive academic research as a knowledge type and knowledge source? How do entrepreneurs incorporate and use academic research as knowledge type and knowledge source?

\subsubsection{Creative Problem Solving and Scientific Inquiry}

Creative problem solving (CPS) and scientific inquiry (SI) go hand in hand, and work together to complete the innovation process. Each has a distinct place and role. CPS and SI, and their contributions, are compared below.

Table 31. Creative problem solving versus scientific inquiry.

\begin{tabular}{|l|l|}
\hline \multicolumn{1}{|c|}{ Creative problem solving (CPS) } & \multicolumn{1}{c|}{ Scientific inquiry (SE) } \\
\hline Advancing solutions. & Validating solutions. \\
\hline More art than science. & More science than art. \\
\hline Imaginary; tentative; hypothetical; possible. & Factual; proven. \\
\hline Subjective. & Objective. \\
\hline Creativity based. & Model and methodology based. \\
\hline Innovation through creativity. & $\begin{array}{l}\text { Innovation through understanding and } \\
\text { comprehension. }\end{array}$ \\
\hline
\end{tabular}




\begin{tabular}{|l|l|}
\hline $\begin{array}{l}\text { Scientific research must first be reinterpreted and made practical, } \\
\text { before it can benefit innovation. }\end{array}$ & Extends CPS. \\
\hline $\begin{array}{l}\text { CPS is more intuitive, less factual based, initially free-thinking and } \\
\text { unconstrained, but subsequently requires evidence and } \\
\text { substantiation. CPS is a lot more open-minded, free and unlimited or } \\
\text { unconstrained. }\end{array}$ & $\begin{array}{l}\text { Confined by paradigms and frames of mind. It is } \\
\text { embedded in a community of same regard and } \\
\text { perspective. }\end{array}$ \\
\hline Informal, unstructured. & Structured, ordered, systematic, and thorough. \\
\hline Innovative, intuitive, original, imaginary, and thus out of the box. & $\begin{array}{l}\text { Methodological, procedural; systematic, } \\
\text { structured; sequential; purposeful; rigorous, } \\
\text { grounded, factual, substantiated, accurate, valid. }\end{array}$ \\
\hline
\end{tabular}

Table 32. The contributions of CPS and SE.

\begin{tabular}{|l|l|}
\hline \multicolumn{1}{|c|}{$\boldsymbol{C P S}$} & \multicolumn{1}{c|}{$\boldsymbol{S E}$} \\
\hline $\begin{array}{l}\text { Provides the general answer. Provides } \\
\text { possibilities and solutions. }\end{array}$ & $\begin{array}{l}\text { Contributes the knowledge base and science the entrepreneur builds on. Can } \\
\text { also advance basic knowledge, and thus open up perspective. } \\
\text { advanced. }\end{array}$ \\
$\begin{array}{l}\text { Plenty of creative thinking. } \\
\text { CPS can not advance very far; can only } \\
\text { mostly hypothesize solutions. }\end{array}$ & $\begin{array}{l}\text { Closes the knowledge gaps associated with possibilities and solutions. } \\
\text { Plenty of evaluation and testing. }\end{array}$ \\
\hline
\end{tabular}

\subsubsection{Science and Research}

If not directly, science and scientific research (SR) contribute indirectly to innovation, and science holds indirect benefit for the entrepreneur. Science forms a strong foundation to build on, and the entrepreneur generally needs to build on such a foundation, and functions from this foundation. Scientific research supports and aids innovation. The entrepreneur uses science in an instrumental manner to a large extent. The view is that the majority of solutions are derived from a scientific approach. Again, understanding something better than your competitors can translate into competitive advantage.

Research and access to research are seen as and have become a key and vital knowledge source. Startups and the concept of startups have emerged and have taken off. A lot more startups as businesses aspire to realize disruptive technology. Entrepreneurship has become more sophisticated, and entrepreneurship and entrepreneurship theory have developed and advanced. The process is accelerated and sped up by knowledge and technology - technology being prevalent, and knowledge and information being readily available.

The entrepreneur may also be looking for non-conventional, innovative solutions to a problem, that breaks from conventional knowledge. Here, science can play an active and supporting role.

Innovation is not necessarily (directly) dependent or reliant on SR. Science and SR are not a (directly) prerequisite for innovation. The opportunity, the nature of the opportunity, its underlying innovation type, its knowledge gaps and requirements, the maturity of the underlying scientific knowledge, as well as time horizons, impact the perceived relevance of SR. Innovation that is more incremental in nature, and that have shorter timelines, may find less relevance in SR. Innovation and creativity may be enough to close the knowledge gaps of an opportunity, and to move the opportunity forward. The distance the entrepreneur is away from SR is an important indicator. The closer he is to it, the more he can utilize it and direct it.

Table 33. Contribution of scientific research.

SR constitutes the starting point, or minimum barrier or entry level. It also constitutes the platform to develop new products from.

Contributes to the entrepreneur's knowledge base. This knowledge base is used to build a framework to understand the world, advance understanding, propose solutions, and to innovate and create new products from. The understanding that science helps with, points out inefficiencies, makes it possible to hypothesize and forecast, and accelerates development and prototyping, by reducing error and misconception.

Science forms a frame of reference and vantage point. It constitutes a way of thinking and reasoning, develops the entrepreneur's thinking and reasoning, and enables structured and systematic thinking.

SR may suggest new ideas or opportunities.

SR may help to move identified opportunities forward and implement it. It provides the entrepreneur with a way to move forward in finding answers and closing knowledge gaps. 
SR guides and gives direction to the entrepreneur. Science and SR can help the entrepreneur to retain focus. It is the first port of call to solve a problem, and from this innovation typically follows. Science can introduce a number of solutions to problems.

SR reveals the future. SR can provide direction in the sense of pointing out where things are heading.

In some industries, science and SR form the backbone and foundation that innovation builds on. Without it, it will not be possible to innovate. A number of problems and solutions are very sophisticated, requiring expert or sophisticated knowledge.

A number of fundamental problems also drive a lot of science, knowledge creation, innovation, and creativity. A lot of innovation typically follows new science and SR. New SR in a field typically leads to new application. It is marvel sciences and scientific premises that contribute to bringing out new products. Science and technology frequently coexist, co-occur, or co-impact, and it can be very powerful when they do. For example, very original and ground-breaking research may permit high technology, or state of the art technology.

Science and SR have become a key platform and launch pad of startups.

The entrepreneur may seek to substantiate his propositions through research, and to build up different sources of evidence. The entrepreneur may be working towards evidence informed decision making - making decisions based on evidence.

The entrepreneur may also be looking for non-conventional, innovative solutions to the problem, that breaks from conventional thinking and knowledge. Science is to help and support him with this.

In working on opportunities and interrogating and resolving opportunities, knowledge and knowledge gaps may explode and widen - open up - such that a lot of new questions are raised. In many cases, the entrepreneur may end with a lot more questions than he started off with, and the entrepreneur's existing knowledge may simply not be enough to resolve the new questions. A lot more SR will then be required to resolve the questions and restore his sense of order.

\section{Table 34. Utility of scientific research.}

The impact or contribution of basic research to opportunities is not immediate. It is believed that basic research contributes very little to entrepreneurial opportunities. The science or research must diffuse first, and this can take time.

Science must be interpreted, applied and contextualized first, to make it practical and relevant. It is not directly applicable.

A strong business case is required, and the business context must be considered: entrepreneurship without a business case may simply be innovation.

The value of science or SR may be dependent on industry or application - whether application can be found for it. Changes in context - events, triggers, and interrupts that cause change - bring new opportunities to rediscover science and SR application.

Scientific method is an important tool for the entrepreneur. In that sense, it can have more relevance to the entrepreneur than SR. The entrepreneur can benefit from and practice informal science just as well.

It may be quicker, more convenient, and more efficient to reference professionals, experts, or groups, to quickly and more quickly get up to speed with where current, existent thinking is. With SR, collaboration may be an option.

Scientific research is mostly beneficial when it is greatly aligned with the opportunity of the entrepreneur.

The question is whether the entrepreneur's opportunity requires SR. Instead of directly or indirectly commissioning SR, the entrepreneur may simply build on existing research.

Scientific research and method are necessary when the entrepreneur tackles very original problems, and when looking for answers and solutions to more principal questions. Mostly when the entrepreneur is innovating completely new, novel processes and so forth, he may need SR to support and substantiate it.

Related to whether the entrepreneur's opportunity requires SR, also important is whether the entrepreneur can, or believes he can, advance the problem or opportunity through other means and sources, just as well. The entrepreneur may prefer to default to practical means, and past experiences, and would employ SR for technical subject matter. There may be ignorance on the side of the entrepreneur, if he ignores SR when it is the best means.

To fill some of his knowledge gaps, the entrepreneur may simply need trial and error or experimentation, as opposed to scientific research.

Conducting SR themselves may be impractical for most small business. However, SMEs can access and read current SR.

When considering the time horizon the entrepreneur considers, is comfortable with, and is willing to commit to, scientific or fundamental research itself may take too long for the entrepreneur to commit to. 
Pillay, D. and Barnard, B., 2019. Entrepreneurship and Knowledge Management: Knowledge Requirements, Utility, Creation, and Competency. Expert Journal of Business and Management, 7(1), pp.44-81.

Lack of time and knowledge can cause the entrepreneur to work around a problem, instead of truly solving it. The entrepreneur may struggle to solve certain problems, source certain knowledge, or to build a comprehensive model of the problem.

Table 35. Scientific research and the entrepreneur.

SR is regarded as very important and beneficial.

The level of scientific understanding necessary by the entrepreneur may vary. He may only need to know the underlying science at a broad level, to be able to innovate, or innovate further.

It is generally easy for entrepreneurs to apply scientific premises to a problem, and they do so regularly.

Some entrepreneurs are very knowledgeable in terms of SR, are very comfortable with it, and regularly digest it. They know exactly how to fully utilize and exploit scientific knowledge, and they are not intimidated or put off by scientific knowledge.

Some entrepreneurs are very technical or scientific in orientation. (In this regard, they also point to acclaimed entrepreneurs, like Elon Musk.)

The entrepreneur may engage and use pure science and SR, as well as more derivative, secondary or applied work that is based on SR, that focuses more on application, relevance, implementation and interpretation.

The entrepreneur generally forms the bridge between SR and its application.

Some entrepreneurs may actively search and try to find applications for scientific knowledge.

A primary task of the entrepreneur is essentially to open up or repackage knowledge. A number of entrepreneurs predominantly repackage scientific knowledge. Entrepreneurial opportunity is seen in repackaging scientific knowledge.

Repackaging knowledge leads to new opportunities. As part of repackaging knowledge, the entrepreneur is continuously left with new questions and hypotheses. The entrepreneur can create markets if he can fill the gap and better guide SR.

Creative thinking may further be combined with SR for even more original thinking.

The entrepreneur constitutes an efficient manager of research. It is the entrepreneur that ensures the economics, profitability, and practicality of research. In this way, the entrepreneur can also accelerate research.

Table 36. Critique and constraints of scientific research.

It may be possible for the entrepreneur to innovate from what he has in front of him, and the knowledge that he currently has.

R\&D is not the only contributor to innovation. There are many forms, types and sources of innovation.

The utility of SR is hindered by: 1) availability, 2) accessibility, 3) readability, 4) ease of use, and 5) application and contextualization (locating, sourcing, recognizing, discovering, identifying SR).

Impediments, like access and time, limit the utility of SR.

High value IP and research-based knowledge may take too long, and may be driven by research or science, rather than customer needs.

Some see SR and scientists as mostly confined to universities and big corporations. Scientists are still very limited and confined in their thinking.

Science may be more used, aligned, structured, and organized for basic research that builds, stimulates and expands knowledge foundations and perspectives. It may not be extensively used to drive new innovation where science unlocks opportunities.

The majority of SR is seen to comprise of "academic research", implying poor focus - research that has little direct and immediate business application.

University research is currently less practical and applicable, and thus also of lower quality, due to alignment - the focus, objectives and incentives of and pertaining to universities.

Researchers do not take industry challenges, etc., that seriously as input for scientific research. Researchers are poorly motivated and incentivized to listen to industry.

Academic research and scientific knowledge should be made relevant, and can be made more accessible. Parts of academic research and papers - the findings for instance - can be made freely available to the public. 
Universities can output a lot more business and market relevant research, and should reconsider their mix and balance with regards to research.

Universities can train more specific entrepreneurship skills, and how to operate in the entrepreneurship space. Universities can help to lower the barriers to and of entrepreneurship.

Overall, it may be required to manage the research process of universities very differently, to align it more to entrepreneurship, and make it more efficient and beneficial - of worth - for entrepreneurship.

What is required and sought is either a lot more applied research, or basic research that is a lot more industry aligned.

Universities should be made more accessible and approachable.

Knowledge referencing - the ability to source, apply and exploit knowledge - should be made easier and faster.

It can be made easier to acquire the knowledge base the entrepreneur requires to get off the ground.

\subsubsection{Social Science}

Social sciences (SS) can help to understand people and communities better, also how people adopt (to) technology. Social research may have greater application for customer and management innovation innovation pertaining to soft issues and aspects. Entrepreneurs work with and win over customers. It always help to understand customers as people better.

SS is a big part of business, and it informs products just as much as natural science. In some ways, SS may even be more important to business and innovation than natural science, because SS informs products just as much as natural science. SS helps to consider the human aspect of innovation and products. SS provides a more comprehensive understanding of social contexts, behaviour and decision making, to complement more scientific knowledge.

Some fields of SS are less- or under-developed, and are receiving less attention. Also, there is room for more practical research that specifically focus on social problems. SS research offers solutions, and can help solve local issues. Online as a different and unique social context or environment, and the difference between offline and online, should receive greater attention.

Social media (SM) is seen as an application or extension of social research. SM does open new doors. There is still room to improve SM. SM avails a completely new avenue of knowledge and information. SM makes it possible to follow social trends and thinking, and to better follow and understand decision processes. It tremendously impacts new product development. It is possible to more closely follow and understand what customers want. It is believed that social data and information will become far richer, with far more diverse and dispersed or embedded sources, that are closer to real events and interactions. It would allow even better understanding of social contexts and environments, and also introduce new social contexts and environments.

\subsubsection{The Impact of Innovation on Science}

Innovation is essentially embedded in science - innovation constitutes a prominent component of science and scientific advancement. Innovation allows scientific development to take place - the scientist is equally innovative or creative in his thinking. The entrepreneur believes his work can contribute to science, particularly when the entrepreneur has reached a certain level.

Innovation or creative work may indirectly contribute to science, by stirring the scientific interest of other parties, like scientists. Innovation can direct science and scientific inquiry. Innovation can point to issues and questions science must pay attention to and resolve. The entrepreneur's work, the interpretations of the entrepreneur, the problems the entrepreneur faces, and the ideas and solutions the entrepreneur comes up with, can inspire scientific research. What the entrepreneur learns can raise additional questions and spark further scientific research and inquiry, and can change and impact the questions asked by science. The practical issues and questions raised can lead to different or additional, principal or basic questions.

Science can extract, incorporate and build on the tacit knowledge of entrepreneurs - it should be a very unique and valuable data source and perspective. It would constitute more balanced and holistic science and scientific research, that make use of all available perspectives and paradigms. The knowledge of entrepreneurs can be tapped and utilized more. To date, this has not been utilized extensively. Academia need to engage with entrepreneurs, to better understand issues. The entrepreneur's understanding of real or practical contexts, etc., and problems, can advance science, by pointing out to science what to focus on, advance and resolve.

Lacking the necessary qualifications may be a barrier to entrepreneurs directly contributing to science, in that the entrepreneur may not be able to deliver a contribution that meets the standards and processes of 
science. Also, the standards of science, or simply/ rather journals, may be too high or impractical. Some journals may be too conformist, traditional and orthodox in their beliefs. As a result, a lot of knowledge and contribution to science (by entrepreneurs) are lost. What is seen as science, and how science and scientific work are evaluated, should perhaps be reassessed.

\subsubsection{Universities and Entrepreneurship \\ Relevance}

Universities have a contribution, and the knowledge they create is valuable, but they are not practical enough, to have a sustainable benefit or advantage. Scientific research is promising, but lacks focus or direction. It is not aligned to entrepreneurs and the opportunities they work on. There occurs very little commercialization of technology from within universities: Innovation and entrepreneurship outside of universities by far overshadow innovation and entrepreneurship within universities.

Table 37. Critique of universities from an entrepreneurship perspective.

Universities, and university output, are poorly aligned to and for entrepreneurship.

University systems are not geared for entrepreneurship.

Universities have the wrong or unbusiness-like mindsets.

The priorities and focus of universities differ from that of entrepreneurs.

Application does not take first priority.

Research is not directly applicable, and must be interpreted and contextualized first.

From an entrepreneurship perspective, it is believed that universities may be pushing their own agenda, and are following their own mandate.

Scientific research is seen as one dimensional and limited.

Academia are not practical - they do not find simple solutions, instead they over-analyze.

Academia are not responsible - they do not deliver the required results in a timely fashion.

Universities can focus on more practical and business minded research.

\section{Opportunity}

One view is that universities are there to teach and educate, not to source opportunities. Universities cannot really help the entrepreneur find opportunities. Thus, universities are poorly positioned or aligned to identify or know of opportunities. Their focus is different. Universities may also lack the necessary business perspective. On the other hand, some believe that universities may provide a specific type of opportunity and contribution. Universities and formal institutions are seen as valuable and viable contributors. Science and scientific research can offer plenty of perspective on problems. Universities are useful, particularly with prototyping. The entrepreneur may use universities for product development and prototyping, and in this regard, universities are extremely beneficial and show a lot of potential. The entrepreneur sees opportunity in (university) research that targets improved efficiency, resource allocation, processes and systems, and sourcing of materials.

A big problem for the entrepreneur when he starts off, is validation or prototyping. The entrepreneur can save costs if a university helps him to validate his work - test if it works. The disadvantage is that the university can steal his idea. Universities, science, and scientific research advance basic research, paradigms and the science base. This opens up tremendous opportunities for entrepreneurs, and universities have an important role to play in this regard. Scientific research generally enables learning, and through learning comes new opportunities. The greater the depth and extent of learning, the greater and more likely is the possibility of new opportunities. To some extent, the type of research is not that relevant, because it is possible to learn from and through, and thus benefit from, all types.

\section{Collaboration}

The need for collaboration is recognized and not contested, but implementation fails to get off the ground and show results. Little exists along the lines of communication and working relationships. 
Table 38. Critique of entrepreneurship collaboration.

\section{Universities and entrepreneurs}

Universities are a crucial part, but only a portion of the total entrepreneurship environment: There are also business culture and climate, competitiveness and innovativeness, also that of the country, etc. Thus, the focus should be on industry-wide collaboration and vision, not just between entrepreneur and universities.

The whole process of entrepreneurship and innovation has changed, and must be made more relevant and efficient. Universities and university collaboration have a part in this.

There is a complete disconnect between entrepreneurs and universities, with no collaboration at all. One does not know what the other does.

Universities are generally detached, secluded, closed to, and inaccessible by entrepreneurs.

Universities may not consider SMEs and entrepreneurs as viable partners to collaborate and work with. Universities are not really seeing the value entrepreneurs offer, and do not view entrepreneurs as a valuable partner - that entrepreneurs can benefit them.

The ideal is where the university goes out of its way to accommodate and support entrepreneurs.

There is a lot of opportunity for entrepreneurs to add value to universities, and what they do. This should lead to more win-win scenarios and cases. Entrepreneurs can contribute a lot of value to universities. Entrepreneurs can help universities to make their research a lot more practical and implementable. The entrepreneur may collaborate with universities and research institutions, to see if (more of) their research work cannot be commercialized. Entrepreneurs can find application for the research of universities, and can help inform universities what to research.

Universities should be more practically aligned - introducing more theory to practice, but that is applicable and relevant. There should be communication between entrepreneurs and universities on problems to tackle, and how the problems can be solved.

Universities have little business sense or understanding, to help them to better align. A lot of potential exists for universities and scientific research to align more with entrepreneurship, and to provide a lot more practical research.

With regards to collaborating with universities, it may be necessary for the entrepreneur to take ownership, initiative and lead. He may need to finance the work, so that he can have greater say over it, and steer it more. University performance then shifts from competency or reputation, to clear outcomes and deliverables, generally set by the entrepreneur and not the university.

Table 39. Critique of entrepreneurship collaboration.

\section{University and industry}

Industry should work with universities. But, because of differences in alignment, universities and industry do not always find it easy to collaborate and work together. Private universities are generally more aligned with industry, and they find it easier to work together.

Universities do not offer holistic, one-stop, practical solutions to industry, but rather hope to specialize, which is seldom practically aligned.

If correctly focused, positioned or utilized, scientific research can have a significant impact, particularly to solve problems and improve quality. For it to work, scientific research must be brought closer to industry and industry technology. The alignment between universities and industry must be improved, and industry application must be clear.

\section{Entrepreneurs and industry}

There should be more collaboration and knowledge sharing between entrepreneurs and big corporations. Entrepreneurs can build and add value on top of existing products and services of big corporations.

Table 40. Critique of entrepreneurship collaboration.

\section{Universities, industry, entrepreneurs}

Certain fields require and can more readily absorb, utilize, and benefit from academic research. Certain projects, private or public, that can be described as cutting edge, state of the art, advanced, or next level, are very original, and open up a lot of doors. Their level of sophistication and scope are extensive. The problems and challenges that accompany them, create new opportunities of high quality. This promises very practical and market-based problems and projects.

The extent of knowledge focus and concentration is important: focusing on and measuring the amount of knowledge created in a location. It should indicate knowledge synthesis in that location, and thus the contribution of and potential for entrepreneurship.

\subsubsection{Research Competency}

It is possible for the entrepreneur to develop research competencies. Scientific research competencies come through experience and learning from others. Effort and input generally pay off. Scientific research can increase efficiency, and reduce wasted effort and the input required. There are basic research competencies involved in knowledge and solution search, and problem solving. 


\section{Discussion}

5.1 What do entrepreneurs perceive as the requirements for knowledge to be a core competency? What do entrepreneurs perceive as knowledge and knowledge creation requirements for entrepreneurship and innovation?

The knowledge consumption, processing, and creation of entrepreneurs can be described as dynamic, rapid, relevant, extensive, and contemporary or up to date.

Entrepreneurs are very dynamic in how they add (value) to, develop, and inflate knowledge. A number of sources are used, a distinct level of creativity is involved, and a lot of knowledge is synthesized.

Knowledge consumption and creation take place at a rapid rate. It is very extensive in scope, and it is accelerated by the availability of knowledge.

When entrepreneurs consume, process, and create knowledge, it is very much with purpose and relevance in mind, and in this regard, entrepreneurs are very much value conscious and value driven. They hardly create knowledge without purpose and value in mind.

Entrepreneurs consume and create knowledge, to remain relevant and up to date, but also in a novel and original sense - knowledge consumption and creation occur at the frontier of novelty and originality, to have relevance, worth and value.

Entrepreneurs synthesize a lot of knowledge, in order to create new knowledge. Knowledge synthesis is a key characteristic of knowledge creation.

Entrepreneurs have a number of access points they consider with regards to knowledge creation. Because value is and must be linked to knowledge creation, different ways of finding inefficiencies, shortcomings, gaps and opportunities, serve as such access or starting points. Also, for the same reason, knowledge creation is also very much related to and intertwined with opportunity. This can involve incremental innovation or radical innovation. Once an opportunity has been identified, the opportunity implementation process is much the same from a knowledge perspective, in the sense that the knowledge gaps of the opportunity must be closed, and in the sense that this would be a prominent focus and objective, regardless of how innovative or radical the opportunity is.

Also, the entrepreneur may either push knowledge, or pull knowledge. He may have a clear idea or opportunity, and may be in the process of sourcing knowledge for it, in order to close any remaining knowledge gaps. Or, he may not yet have a clear idea or opportunity in mind, and may peruse knowledge sources for inspiration. He will do so, without truly knowing what to look for, until an opportunity comes to mind and surfaces.

Radical opportunities, related to radical innovation, and as very original and novel ideas and conceptions, may simply come from very extensive, well-developed and novel knowledge bases.

The relationship between knowledge and innovation, is not straightforward. Although there are exceptions, it is the expectation and belief that the more radical (original) the knowledge, the more radical (original) the opportunity, or vice versa. However, arguably not all radical innovations originate from what would be described as radical knowledge. In these cases, it is believed that a radical (original) knowledge base is still present, and that the radical opportunity associated with the radical innovation, originated from such a radical knowledge base. It is seen as sufficient to define or measure the radicalness or radicality of a knowledge base as relative to that of others, or the "common" or "average" knowledge base.

It is then possible to expand this to, and as, the relationship between knowledge, innovation and creativity. Even though creativity may be involved, and it may be the view that creativity is the differentiating factor in a particular case, rather than knowledge per se, it is questioned whether radical innovation derived from and through creativity, without an underlying radical knowledge base - that is, based on a common knowledge base - is possible: Given the stipulated conditions, particularly the presence and existence of a common knowledge base, and creativity as the predominant catalyst of the innovation, the probability that the opportunity will be recognized is high in general, such that the probability that the opportunity has not yet been recognized, and is still available, is low. Creativity might be a mediating factor, but it is believed that a radical, or simply a non-common, knowledge base is required for an original innovation as a non-common, nonordinary, non-routine innovation. Creativity is then viewed as the processing and reinterpretation of knowledge in an unique and original way - offering unique perspective. 


\begin{tabular}{|l|l|l|l|}
\cline { 3 - 4 } \multicolumn{2}{c|}{} & \multicolumn{1}{c|}{ New knowledge } \\
\cline { 3 - 4 } \multicolumn{2}{c|}{} & \multicolumn{1}{c|}{ Low } & \multicolumn{1}{c|}{ High } \\
\hline \multirow{2}{*}{\begin{tabular}{l} 
Incremental innovation (II) \\
\cline { 2 - 4 }
\end{tabular}} & Radical innovation (RI) & $\begin{array}{l}\text { 3) RI without a lot of new } \\
\text { knowledge. }\end{array}$ & 4) RI with a lot of new knowledge. \\
\hline
\end{tabular}

Figure 2. The relationship between knowledge and innovation.

\begin{tabular}{|c|c|c|c|}
\hline & & \multicolumn{2}{|c|}{ New knowledge } \\
\hline & & Low & High \\
\hline \multirow{2}{*}{ 党 } & Low & 1) Little real innovation. & $\begin{array}{l}\text { 2) Knowledge innovation. Radical innovation is } \\
\text { possible. Perhaps more scientific-based } \\
\text { innovation. }\end{array}$ \\
\hline & High & 3) Typical (class of) incremental innovation. & 4) High quality radical innovation. \\
\hline
\end{tabular}

Figure 3. The relationship between knowledge, creativity, and innovation.

The entrepreneur's knowledge base plays an important role with regards to the opportunities he identifies, and can and will identify. The quality of the opportunities themselves also determine the quality of the innovation - high value innovation requires commencing with a high value opportunity or idea, rather than adding to an idea or opportunity along the way. Yet, a number of mediating factors determine the outcome, and the effectiveness of his knowledge base. This would include factors like culture, support, preference, risk propensity, and so forth.

5.2 How do entrepreneurs perceive academic research as a knowledge type and knowledge source? How do entrepreneurs incorporate and use academic research as knowledge type and knowledge source?

Even though critical for innovation, opportunity, and ideation, original and creative thought, associated with creative problem solving, can only take the entrepreneur so far. It generally lacks and requires technical details, and is normally subsequently combined with knowledge, facts, and even research, to close knowledge gaps and resolve its practical implementation. Creative and original thought are the entrepreneur's left foot, whilst his knowledge base, knowledge in general, and science are his right foot. The entrepreneur needs both to advance and progress.

Entrepreneurs vary in the extent that they utilize SR and find SR relevant. Science and SR add to the knowledge base of the entrepreneur, and for this reason, many entrepreneurs will peruse and consume SR, to build and expand their knowledge base, and also to find answers. A smaller number actively directly or indirectly engage in or commission SR. Many work on more incremental innovation type opportunities, that do not require extensive $\mathrm{SR}$, or SR that is not yet available.

A number of factors restrict the utility of SR, like the timelines thereof, as well as the availability, accessibility, relevance and application thereof.

SR is either pushed or pulled. To commission SR directly or indirectly, the entrepreneur generally must be working on an opportunity that demands it, and this may be limited. Or, the entrepreneur must take SR as output, and seek application for it. In this case, the quality or relevance of SR is important. Yet, current SR output is not highly rated.

Collaboration, particularly between universities and entrepreneurs, can be described as non-existent. Some of the factors that contribute to this, include: focus and alignment. Little communication and knowledge sharing take place. In general, universities produce research as output that entrepreneurs can not apply, or directly apply, and first have to seek relevance for (if any can be found). There is too little communication so that the relevant parties can work out how to benefit each other.

\section{Summary}

To be a core competency, knowledge creation in turn requires competencies related to: 1) speed - the ability to process vast and diverse knowledge sources, and synthesize it into new knowledge; 2) creativity - in the sense of original thought; 3 ) originality, relevance, and pertinence - the ability to be abreast of, and ahead of, developments, and to operate at the frontier of developments, innovation and progress. It implies having 
foresight, and being informed, modern and advanced; 4) and business acumen - the ability to create knowledge that has value, and to create a business case around knowledge, and knowledge creation. Also, it requires an extensive and well developed knowledge base.

The knowledge and knowledge creation requirements of entrepreneurs and innovators also much depend on the opportunities they work on. The type of problems and innovations they work on, determines the type and extent of the knowledge gaps they face and need to fill.

Entrepreneurs and innovators can push or pull knowledge. They can source knowledge to implement opportunities, or they can source opportunities from knowledge.

Although the relationship between knowledge and innovation is not that straightforward, it is expected that the more radical the knowledge, the more radical the opportunities it enables. Also, the more radical the opportunity, the more radical the knowledge it requires.

Given that not all radical innovation is likely instigated by radical knowledge, it is further expected that most radical innovations build on radical knowledge bases, simply defined as non-conventional knowledge bases. Creativity then serves as mediating factor. The innovation opportunity of conventional knowledge bases is seen as low, because they would be largely exploited.

SR adds to and expands the entrepreneur's knowledge base. Just like knowledge, SR can be pushed or pulled. Pulling SR would imply the entrepreneur requires SR for his innovation. Pushing SR would mean entrepreneurs find practical application for SR output. Few entrepreneurs work on opportunities that require SR. SR output is seen as not relevant and applicable, and this affects its value. Too little collaboration takes place between entrepreneurs and researchers, to effectively and mutually contribute to and guide each other.

\section{Future Research}

The following can be researched further:

1. Constructing a measure of knowledge, also as a measure of the capability and readiness of the entrepreneur: how much knowledge does the entrepreneur possess or have access to, and what is the quality thereof, based on aspects like the scope, depth, relevance and uniqueness of the knowledge.

2. The above measure can also be extended to a measure of the entrepreneur's knowledge competency: his capacity to process knowledge, his ability to synthesize knowledge, and his display of creativity and novelty in this regard.

3. A measure of knowledge creation, and knowledge innovation: In this regard, the value of the knowledge might be a complication, particularly if the desire is to restrict the measure to valuable knowledge created. Nevertheless, it can be proxied by patents, as well as manpower (man-hours) and expenditure on knowledge creation. But, a more immediate or direct measure may be new opportunities suggested and unlocked, and new implementations that resulted from the knowledge, or its contribution to the growth of the knowledge base.

4. A measure related to knowledge bases, and the quality thereof. Such a measure would build on the depth, scope, relevance (currency), and the uniqueness or differentiation of the knowledge base.

5. The relationship between knowledge and innovation, based on measures of the extent and quality of knowledge created, and the extent and quality of the resultant innovation.

6. The relationship between knowledge base and innovation, based on the extent, quality and differentiation of the knowledge base, and the extent and quality of the resultant innovation.

7. The relationship between creativity, knowledge, and innovation, based on the type, quality and extent of knowledge creation, the type, quality and extent of the resultant innovation, and how creativity was used to process knowledge as input, into innovation as output.

8. The potential of and for applied research: the room for, and benefit that can be derived from, more applied research, as well as the areas and topics that would benefit most, or offer the most value.

9. Collaboration between entrepreneurs and universities: 1) the collaboration strategy of universities: how universities can best benefit from collaboration with entrepreneurs; 2) an evaluation of collaboration programs between universities and entrepreneurs; 3 ) obstacles to collaboration, as perceived by entrepreneurs and researchers; 4) focus groups, and action learning, that consider and discuss collaboration, and the problems entrepreneurs and universities can collaborate on; 5) the openness and entrepreneurshipreadiness of universities.

10. The practicality and relevance of university research.

11. An evaluation of the (research) problems entrepreneurs presently struggle with and can suggest.

12. Innovation policy that involve and combine both universities and entrepreneurs.

13. Social science and entrepreneurship: How social science can further benefit and contribute to entrepreneurship. 
14. A comparative study of the knowledge-skills, -competencies, and -bases of novice entrepreneurs, vis-a-vis that of experienced entrepreneurs, particularly to establish whether aspects related to knowledge explain entrepreneurial success.

\section{References}

Adams, R. M., 1997. Social contexts of technology. Social Research, pp.947-964.

Ahuja, G., and Katila, R., 2004. Where do resources come from? The role of idiosyncratic situations. Strategic Management Journal, 25(8-9), pp.887-907.

Alavi, M., and Leidner, D. E., 2001. Knowledge management and knowledge management systems: Conceptual foundations and research issues. MIS quarterly, pp.107-136.

Anderson, C., 2008. The end of theory: The data deluge makes the scientific method obsolete. Wired magazine, 16(7), pp.16-07.

Beukel, K., Valentin, F., and Jensen, R. L., 2014. How Search in Science Impacts on the Value of Inventions at Early and Late Stages in the R\&D cycle. Paper presented at the DRUID Society Conference.

Blackler, F., 1995. Knowledge, knowledge work and organizations: An overview and interpretation. Organization studies, 16(6), pp.1029.

Bozeman, B., Fay, D., and Slade, C. P., 2013. Research collaboration in universities and academic entrepreneurship: the-state-of-the-art. The Journal of Technology Transfer, 38(1), pp.1-67.

Brooks, H., 1994. The relationship between science and technology. Research policy, 23(5), pp.477-486.

Castellanos, A. R., Rodriguez, J. L., and Ranguelov, S. Y., 2004. University R\&D\&T capital. Journal of Intellectual Capital, 5(3), pp.478-499.

De Jong, T., and Ferguson-Hessler, M. G., 1996. Types and qualities of knowledge. Educational psychologist, 31(2), pp.105-113.

Esteves, J., Chan, R., Pastor, J., and Rosemann, M., 2003. An exploratory study of knowledge types relevance along enterprise systems implementation phases. Paper presented at the $4^{\text {th }}$ European Conference on Organizational Knowledge and Learning Capabilities.

Faulkner, W., 1994. Conceptualizing knowledge used in innovation: A second look at the science-technology distinction and industrial innovation. Science, technology, and human values, 19(4), pp.425-458.

Furlong, J., and Oancea, A., 2005. Assessing quality in applied and practice-based educational research: A framework for discussion. Review of Australian research in education: counterpoints on the quality and impact of educational research - a special issue of the Australian Educational Researcher, 6, 89104.

Goethner, M., Obschonka, M., Silbereisen, R. K., and Cantner, U., 2012. Scientists' transition to academic entrepreneurship: Economic and psychological determinants. Journal of Economic Psychology, 33(3), pp.628-641.

Grimaldi, R., Kenney, M., Siegel, D. S., and Wright, M., 2011. 30 years after Bayh-Dole: Reassessing academic entrepreneurship. Research Policy, 40(8), pp.1045-1057.

Gupta, A. K., and Govindarajan, V., 2000. Knowledge flows within multinational corporations. Strategic management journal, 473-496.

Haeussler, C., and Colyvas, J. A., 2011. Breaking the ivory tower: Academic entrepreneurship in the life sciences in UK and Germany. Research Policy, 40(1), pp.41-54.

Haig, B. D., 1995. Grounded theory as scientific method. Philosophy of education, 28(1), pp.1-11.

Heilprin, L. B., 1995. Science and technology: From prescientific times to the present. Journal of the American Society for Information Science (1986-1998), 46(8), p.574.

Hong, S., 1999. Historiographical layers in the relationship between science and technology. History and technology, 15(4), pp.289-311.

Huber, G. P., 1991. Organizational learning: The contributing processes and the literatures. Organization science, 2(1), pp.88-115.

Keller, K. H., 2008. From here to there in information technology: the complexities of innovation. American behavioral scientist, 52(1), pp.97-106.

Klofsten, M., and Jones-Evans, D., 2000. Comparing academic entrepreneurship in Europe-the case of Sweden and Ireland. Small Business Economics, 14(4), pp.299-309.

Lam, A., 2000. Tacit knowledge, organizational learning and societal institutions: An integrated framework. Organization studies, 21(3), p.492.

Laukkanen, M., 2003. Exploring academic entrepreneurship: drivers and tensions of university-based business. Journal of Small Business and Enterprise Development, 10(4), pp.372-382. 
Lee, A. S., 1989. A scientific methodology for MIS case studies. MIS quarterly, pp.33-50.

Lee, C., Park, G., and Kang, J., 2016. The impact of convergence between science and technology on innovation. The Journal of Technology Transfer, 43(2), pp.522-544.

Markus, L. M., 2001. Toward a theory of knowledge reuse: Types of knowledge reuse situations and factors in reuse success. Journal of management information systems, 18(1), pp.57-93.

Pannell, D. J., 1999. On the balance between strategic-basic and applied agricultural research. Australian Journal of Agricultural and Resource Economics, 43(1), pp.91-113.

Pavitt, K., 1998. The social shaping of the national science base. Research policy, 27(8), pp.793-805.

Powers, J. B., and McDougall, P. P., 2005. University start-up formation and technology licensing with firms that go public: a resource-based view of academic entrepreneurship. Journal of business venturing, 20(3), pp.291-311.

Rip, A., 1992. Science and technology as dancing partners. In Technological development and science in the industrial age (pp. 231-270): Springer.

Rosenberg, N., and Nelson, R. R., 1994. American universities and technical advance in industry. Research policy, 23(3), pp.323-348.

Suenaga, K., 2016. A Diagrammatic Model of Technological Paradigms and Technological Trajectories: The Emergence and Hierarchy of Technological Paradigms.

Toole, A. A., and Czarnitzki, D., 2007. Biomedical academic entrepreneurship through the SBIR program. Journal of Economic Behavior and Organization, 63(4), pp.716-738.

Walsh, J. P., and Ungson, G. R., 1991. Organizational memory. Academy of management review, 16(1), pp.5791.

Windschitl, M., Thompson, J., and Braaten, M., 2008. Beyond the scientific method: Model-based inquiry as a new paradigm of preference for school science investigations. Science education, 92(5), pp.941-967. 